\title{
Platelets in defense against bacterial pathogens
}

\author{
Michael R. Yeaman
}

Received: 5 November 2009/Accepted: 5 November 2009/Published online: 15 December 2009

(C) The Author(s) 2009. This article is published with open access at Springerlink.com

\begin{abstract}
Platelets interact with bacterial pathogens through a wide array of cellular and molecular mechanisms. The consequences of this interaction may significantly influence the balance between infection and immunity. On the one hand, recent data indicate that certain bacteria may be capable of exploiting these interactions to gain a virulence advantage. Indeed, certain bacterial pathogens appear to have evolved specific ways in which to subvert activated platelets. Hence, it is conceivable that some bacterial pathogens exploit platelet responses. On the other hand, platelets are now known to possess unambiguous structures and functions of host defense effector cells. Recent discoveries emphasize critical features enabling such functions, including expression of toll-like receptors that detect hallmark signals of bacterial infection, an array of microbicidal peptides, as well as other host defense molecules and functions. These concepts are consistent with increased risk and severity of bacterial infection as correlates of clinical abnormalities in platelet quantity and quality. In these respects, the molecular and cellular roles of platelets in host defense against bacterial pathogens are explored with attention on advances in platelet immunobiology.
\end{abstract}

Keywords Platelets - Host defenses - Bacteria . Pathogen · Interactions

\footnotetext{
M. R. Yeaman ( $\square)$

Division of Infectious Diseases, St. John's Cardiovascular

Research Center, Harbor-UCLA Medical Center,

David Geffen School of Medicine at UCLA,

1124 West Carson Street, RB-2, Torrance, CA 90502, USA

e-mail: MRYeaman@ucla.edu
}

\section{Platelets: the other white cells}

Invertebrates contain specialized dual-function cells called hemocytes, which act to maintain hemostasis and defend against microbial pathogens. These unique cells limit hemolymph loss upon tissue injury, engage microorganisms introduced by trauma, and coordinate tissue remodeling and wound repair [1-3]. In higher organisms including mammals and marsupials, platelets, leukocytes, and lymphocytes are often viewed as independently mediating hemostasis, inflammation, and immune regulation, respectively $[4,5]$. Of course these cells interact with one another in many ways. Nonetheless, while mammalian platelets may be best known for their maintenance of hemostasis, these understudied cells have retained features of archetypal inflammatory cells corresponding to multiple functions in antimicrobial host defense.

Platelet roles in host defense have been the topic of recent reviews [1, 6-11]. Thus, the focus of the following discussion is to provide a framework of understanding the antimicrobial structures and functions of platelets in defense against bacterial pathogens.

Platelets are ancient granulocytes

Platelets are small $(2-4 \mu \mathrm{m})$, discoid cells that originate from megakaryocyte lineage [12-16]. Platelets have a life span in the peripheral bloodstream of 5-10 days. These anucleate cells can perform protein translation using stable mRNA templates originating from their megakaryocyte precursors [1, 6-9]. Mature platelets have three distinct types of cytoplasmic granules. Dense $(\delta)$ granules are rich in mediators of vascular tone, such as serotonin, adenosine diphosphate (ADP), calcium, and phosphate [1, 17]. In contrast, alpha $(\alpha)$ granules store proteins specialized to 
hemostatic functions, including adhesion (e.g., fibrinogen, thrombospondin, vitronectin, laminin, and von Willebrand factor), coagulation (e.g., plasminogen and $\alpha_{2}$-plasmin inhibitor), and endothelial cell repair [e.g., platelet-derived growth factor (PDGF), permeability factor, and transforming growth factors $\alpha$ and $\beta$ (TGF- $\alpha$ and TGF- $\beta$ )] [1, 69]. Platelet $\alpha$-granules also store an array of microbicidal proteins (see below). Lysosomal $(\lambda)$ granules contain enzymes that modulate thrombus dissolution [6-9, 17]. When activated, platelets respond in specific ways that emphasize their multiple roles in antimicrobial host defense, including: (1) activated metabolic status; (2) metamorphosis from discoid to ameboid shape; (3) expression of receptors mediating increased adhesivity to injured or infected tissues; (4) vectored motility toward and intensification at sites of tissue injury or infection; (5) generation of reactive oxygen species including superoxide, peroxide, and hydroxyl radicals; (6) extension of pseudopodia that interact with microbial pathogens as well as host cells; (7) cytoskeletal remodeling to facilitate granule mobilization and organization; and (8) degranulation and processing of preformed granule molecules, including host defense peptides (see below). The distinct platelet granules are subject to synchronous or dysynchronous release, depending upon agonist specificity and potency. For example, low levels of thrombin or ADP induce $\delta$ and $\alpha$ degranulation, whereas $\lambda$ granules are not secreted until such agonists accumulate to much higher concentrations [6-9, 18-20].

Platelets serve roles that recapitulate and complement cell-mediated immune effector cells. In vitro and in experimental animal models, platelets intensify at sites enriched in microbial stimuli such as $N$-formyl-methionylleucyl-phenylalanine ( $N$-f-met-leu-phe) [29] or complement proteins C3a and C5a [1, 7, 25, 30]. Experiments by Czapigaa et al. show that platelets express the formyl peptide receptor (FPR), and surfaces of activated platelets specifically ligate $N$-formyl peptides, followed by calcium mobilization [31]. Gradient-mediated chemotaxis of platelets occurs in response to formyl peptides. Notably, endogenous $N$-formyl peptides liberated from mitochondria of necrotic host cells evoke platelet chemotaxis via FPR recognition; however, cells undergoing apoptotic cell death do not appear to induce platelet chemotaxis. Such relationships further implicate archetypal phylogenetic origins of platelets in host defense against infection.

The concept that platelets contribute to host defense against infection is substantiated by a line of evidence relevant to platelet structure and function. For example, platelets and professional phagocytes such as neutrophils and monocytes share common surface antigens: the $40-\mathrm{kDa}$ Fc $\gamma$ RII receptor [21], Fc\&RI receptor for IgE [22], $\mathrm{C}$-reactive protein receptor [23], and the thrombospondin receptor CD36 (platelet GPIV) [24]. Platelets also express complement CR3 receptor [25], receptors for C3a and C5a products of complement fixation, and sense and respond to cytokines such as tumor necrosis factor- $\alpha$ (TNF- $\alpha)$, interleukin-1 (IL-1), and IL-6 in a manner similar to leukocytes [26, 27]. Clemetson et al. [28] reported that human platelets express functional chemokine receptors, including CCR1, CCR3, CCR4, and CXCR4.

As discussed below, platelets interact directly and indirectly with a broad variety of microbial pathogens, and can internalize microorganisms, likely enhancing pathogen clearance from the bloodstream [1, 32, 33]. Platelets stimulated through interactions with microbes or their signals generate reactive oxygen species that exert direct antimicrobial activity. Similar to neutrophils and macrophages, granules of activated platelets are mobilized by microtubule assembly, and subsequently secrete. However, in contrast to leukocyte degranulation directed to intracellular phagolysosomes, platelet degranulation directs the majority of granule constituents to the extracellular milieu. Taken together, these characteristics strongly support the concept that platelets are ancient granulocytes that recognize signals and organisms relevant to settings of infection, and respond at these sites to confer important host defense functions.

Platelets bridge innate and adaptive immunity

Platelets make an array of constitutive and inducible receptors that confer these cells the ability to sense and respond to hallmark signals of infection. To do so, platelets express several toll-like receptors (TLRs) that recognize cognate pathogen-associated molecular patterns (PAMPs). Thus, platelets function as sentinel cells to detect the presence of potentially harmful microbes. For example, quiescent CD41(+) platelets express low levels of TLR2, TLR4, and TLR9 on their surface. Expression of these TLRs is significantly increased upon platelet activation [34]. For example, thrombin activation induces significant upregulation of TLR9 expression, and human platelets express TLR1 and TLR6, particularly in settings of vascular lesions potentially mediated by bacterial infection [35]. In addition, bacterial LPS causes increased expression of functional TLR4 in vivo, and such activation and TLR expression appears to promote tumor-necrosis factor alpha (TNR- $\alpha$ ) expression [36]. Cognasse et al. [37] recently showed that LPS stimulates platelet release of cytokines, platelet microbicidal proteins, and kinocidins by way of TLR4. Of note, incubation of isolated platelets with a synthetic TLR1/TLR2 agonist directly induces platelet aggregation and collagen adherence [38]. Stimulation of platelet TLR2 also increased platelet surface expression of P-selectin and integrin glycoprotein IIb/IIIa, generation 
of reactive oxygen species, and, generation of plateletneutrophil aggregates in whole human blood.

Despite such structural and functional evidence relating to roles in innate immunity, platelets have traditionally been viewed only as cellular fragments incapable of complex molecular pathways. This view is currently evolving. It is now known that platelets express constituents of the lipopolysaccharide (LPS) receptor-signaling complex, including toll-like receptor-4 (TLR4), TLR2, TLR9, CD14, MD2, and MyD88. Zhang et al. [39] have demonstrated that LPS evokes platelet activation and secretion conferred by a TLR4-mediated process. Here, LPS caused platelet $\delta$ - and $\alpha$-degranulation as shown by ATP release and P-selectin expression, respectively. The platelet response to LPS was eliminated in the presence of $\alpha$-TLR4 antibody, or using platelets from TLR4 knockout animals. Further, LPS-induced platelet aggregation and thrombus formation were mitigated in MyD88 null mice. This LPS-mediated cGMP upregulation was inhibited by $\alpha$-TLR 4 or TLR4 deficiency, implicating that platelets respond to LPS through a cGMP/protein kinase G pathway linked to TLR4. These findings suggest that platelets are indeed capable of TLR-mediated sense and response functions important to effector roles in host defense.

Interestingly, platelet TLR4 has emerged in a putative new mechanism of host defense. Clark et al. [40] have suggested that platelet TLR4 detects cognate ligands in blood, inducing platelet adhesion and subsequent neutrophils adherence. This sense and response relay yields vigorous neutrophil activation and subsequent formation of neutrophil extracellular traps (NETs). The formation of bacterial-capturing NETs was predominant in fenestrated tissues such as the liver sinusoids and pulmonary capillaries, where bacterial trapping is most efficient. Hence, it is possible that platelet TLR4-mediated responses to bacteria lead to platelet-neutrophil interactions that enhance bacterial clearance.

It should be noted that thrombocytes, ancestral nucleated platelets from vertebrates earlier than mammalian or marsupial, also express TLRs that mediate important host defense functions. For example, Scott et al. [41] found that avian thrombocytes express IL-6 and COX-2 mRNA in response to LPS via a TLR4 pathway. As a result, bioactive prostaglandin PGE2 is generated. Importantly, the inhibition of IKK-2 mitigated COX-2 expression, yielding reduced $\mathrm{PGE}_{2}$ accumulation. These findings suggest that MAP kinase pathways are in play in COX-2 and $\mathrm{PGE}_{2}$ production, but not IL- 6 expression in these cells. In related studies, platelets have been shown to enhance neutrophil oxidative burst in response to Gram-positive as well as Gram-negative bacteria [42]. Moreover, Bennett et al. demonstrated that platelets participate in the regulation of B- and T-lymphocyte- and immunoglobulin-mediated immune responses via CD40/ligand-CD40 interactions [9]. Similarly, Blumberg et al. [43] hypothesized that soluble CD40 ligand (CD154) supernatants of stored platelets can induce cytokines, chemokines, and lipid mediators through activation of CD40-receptor-bearing cells. Although preliminary, such themes support the emerging concept that platelets actively participate in bridging the innate and adaptive immune response to infection.

Taken together, the expression of various TLRs, and an ability to bridge interactions with neutrophils and perhaps $\mathrm{T}$ and $\mathrm{B}$ cells suggests mechanisms through which platelets may directly or indirectly detect bacterial pathogens by recognition of molecular patterns and early warning signals of infection, and then contribute to optimization of immune response.

Platelets sense bacterial infection of endothelium

Beyond their ability to detect microbes themselves, platelets are exquisite sensors for signals of endothelial infection. Endothelial cells damaged by infection undergo changes in surface protein repertoires and secretory profiles that activate platelet responses. Distinct platelet receptors sense agonists and bind to ligands on the surface of activated endothelial cells, or exposed subendothelium due to infection or tissue invasion. Signals detected by platelet membrane glycoprotein (GP) receptors include: collagen [(GPVI and $\alpha 2 \beta 1$ (VLA-2 or GPIa-IIa), fibronectin ( $\alpha 5 \beta 1$ or VLA-5), laminin $(\alpha 6 \beta 1$ or VLA-6), von Willebrand factor (GPIb-IX-V), vitronectin (integrin $\alpha \mathrm{V} \beta 3$ ), and thrombin] [1, 6-10]. Contact with blood or microbes induces tissue factor release from subendothelial stroma, thereby catalyzing thrombin production $[1,44-46]$. Thrombin is a potent platelet agonist $[1,7,17]$, which induces expression of ensuing platelet receptors, including the fibrinogen receptor [integrin $\alpha \mathrm{IIb} \beta 3$ (GPIIb-IIIa)]. Activated platelets also undergo metamorphosis from a discoid to ameboid form, along with microtubule assembly and granule reorganization [47, 48]. Degranulation follows, releasing an array of bioactive molecules, including ADP from $\delta$-granules, and generating thromboxane $\mathrm{A}_{2}$ and platelet-activating factor (PAF) through activation of membrane phospholipase $\mathrm{A}_{2}[1,7,17]$. These potent agonists trigger subsequent waves of platelet activation at sites of tissue colonization, promoting an accumulation of antimicrobial proteins from $\alpha$-granules ([49]; also see below). In addition, P-selectin (CD62P) is exposed on the activated platelet plasma membrane, potentiating leukocyte rolling and eventual recruitment to these sites.

Platelets accumulate at sites of tissue infection

Platelets are the earliest and most numerous cells to accumulate at sites of vascular infections [50-60], 
including: infective endocarditis, suppurative thrombophlebitis, mycotic aneurysm, septic endarteritis, catheter and dialysis access site infections, and infections of vascular prostheses and stents. The rapid and intensive accumulation of platelets at these sites has long been known. In 1886, Osler [61] reported perhaps the first observation of platelets rapidly coating filaments introduced into animal blood vessels. Subsequently, Cheung and Fischetti [62] and others demonstrated that platelets are the first cells to adhere to indwelling vascular catheters. Similarly, platelets rapidly adhere to cardiac valve prostheses and vascular stents [60], and are abundant cells in early phases of endocarditis vegetations in rabbits and humans. Once again, such rapid and targeted responses to sites of tissue injury or microbial invasion support a specific role for platelets in host defense.

\section{Subversion of platelet functions by bacterial pathogens}

Vascular infections caused by virulent bacterial pathogens such as Staphylococcus aureus have traditionally been considered to proceed through multiple phases: (1) adherence of hematogenous pathogens to normal or compromised vascular endothelium (e.g., rheumatic conditions, proximal to artificial device such as a stent or prosthetic valve, etc.); (2) endothelial cell expression of selectins and secretory agonists that promote platelet activation, adhesion, and platelet/fibrin matrix formation [1, 63, 64]; and (3) ensuing deposition of circulating platelets in response to successive waves of agonists (e.g., thromboxane $\mathrm{A}_{2}$, ADP, PAF), or ligands (e.g., integrin $\alpha \operatorname{IIb} \beta 3$ ) associated with secondary platelet activation $[1,7,17]$. Less virulent pathogens, such as viridans streptococci, are thought to require pre-existing abnormalities or injury to endothelial surfaces to initiate endovascular infection through indirect pathways: (1) fibrinogen-mediated adherence to intact or abnormal vascular endothelium or non-bacterial thrombotic vegetations [1, 54]; (2) vascular endothelial cell expression of platelet ligands and agonists (see above); and (3) further platelet/fibrin deposition and evolution of the lesion [1, 7, 10]. In either case, platelets localize to sites of infection of the vascular endothelium, and represent the most rapid and abundant inflammatory cells that respond to endothelial cell damage or microbial colonization. Thus, platelets represent the earliest opportunity for inflammatory responses to intercede in host defense against vascular infection.

Studies over the last two decades have clearly demonstrated that platelets have explicit roles in antimicrobial host defense. Yet, historically, platelets were viewed as promoting the establishment and evolution of endovascular infection $[1,7,53,65,66]$. Early studies were interpreted to suggest that platelets facilitate microbial adhesion to fibrin matrices or endothelial cells in vitro [66]. Subsequent data demonstrated that bacterial and fungal pathogens can aggregate human and rabbit platelets in vitro [67-69]. Herzberg et al. [71] hypothesized that streptococcal binding to and aggregation of platelets may increase virulence of these strains in experimental animal models of endocarditis. Platelet aggregation has also been hypothesized to be detrimental to the host, since massive endovascular vegetations can be associated with clinical complications such as emboli and infarcts [72]. Finally, some investigators have suggested that platelet aggregation and enclosure of microorganisms in platelet-fibrin matrices may protect pathogens from antibiotics or clearance by neutrophils or other leukocytes [73].

Platelets have known antimicrobial structures and functions, and interact with bacteria and other pathogens directly and indirectly. Moreover, no studies substantiate the concept that platelets inherently facilitate microbial pathogenesis or inhibit the immune response. Rather, evolutionary adaptation would have almost certainly selected against such cells. Therefore, the consequences of platelet interaction with bacteria or other pathogens likely rests on the efficacy platelet antimicrobial mechanisms or their interaction with other immune defenses versus the ability of a pathogen to circumvent or survive in the face of such mechanisms.

\section{Platelets interact with bacterial pathogens}

Platelets interact with all kingdoms of microbial pathogens, including viruses, bacteria, fungi, and protozoa. However, platelets interact with distinct types of pathogens in different ways. Such interactions may be direct or indirect, and can yield significant antimicrobial responses and mechanisms. As thorough reviews of such interactions have been previously compiled [1, 6-10, 17], the following discussion focuses on interactions between platelets and human bacterial pathogens. These interactions are viewed with an emphasis on key themes and recent advances in understanding this host-pathogen relationship.

Key events in platelet-bacterial relationships

Platelets engage bacterial pathogens directly and indirectly in vitro and in vivo. The earliest methodical studies of such relationships were those of Clawson and White [73-76]. In their studies, bacterial pathogens were shown to adhere to, aggregate, activate, and prompt degranulation of human and other mammalian platelets. Typically, the sequence of events associated with platelet-bacterial interaction proceeds through distinct and progressive phases: (1) direct contact, (2) morphogenesis, (3) initial aggregation, and (4) 
irreversible aggregation [74]. As this process evolves, platelets undergo a significant shape change from resting discoid cells to ameboid forms that form multiple pseudopodia. This shape transition typically occurs well in advance of platelet aggregation, leading to platelet microtubule organization such that granules are mobilized from the platelet perimeter to the cytoplasm [75]. This organization of granules precedes platelet degranulation [76] and secretion of an array of host defense molecules (also see below).

Diverse bacterial genera, and even different species of the same genus, may differentially adhere to, activate, aggregate, and induce platelet degranulation. For example, Clawson and White, and many platelet scientists since, have shown that Streptococcus pyogenes, Staphylococcus aureus, Enterococcus faecalis, and Escherichia coli rapidly adhere to and promote aggregation of human platelets in vitro [73-76]. Beyond these organisms, diverse pathogenic species interact with and aggregate platelets in vitro, including Fusobacterium [77], Listeria [78], Mycobacterium [79], Pseudomonas [80], Salmonella [81, 82], and Yersinia [83]. In contrast, bacteria that gain entry into the bloodstream, including Staphylococcus epidermidis and Streptococcus pneumoniae, do not trigger irreversible platelet aggregation [74]. Thus, the consequences of bacterial interactions with platelets adherence, activation, and antimicrobial response profile likely significantly influence host defense versus virulence of a given pathogen. The following section considers platelet interactions with staphylococci, streptococci, and notable Gram-negative pathogens such as prototypic bloodstream pathogens in these respects.

Staphylococcal interactions with platelets

Species of the genus Staphylococcus are currently the most frequent etiologic agents of infective endocarditis ([84-86]), and the second most frequent agents of bacteremia [87-89]. The incidence of $S$. aureus invasive infections continues to increase sharply [90], and now occurs in up to 20,000 new patients per year in the United States alone [91-93]. Even with modern advances in antistaphylococcal therapy and endovascular surgery methods and devices, the 1-year mortality of these infections approximates $40 \%$ [86-93]. More concerning still is the global burgeoning in $S$. aureus resistance to conventional antimicrobial agents and strategies [94, 95].

Aside from Streptococcus spp., the interactions of platelets and with staphylococci, and in particular S. aureus, have been the most well-characterized. Traditionally, investigations focused on two distinguishable but complementary facets of this relationship: (1) toxins and other secretory and capsular components; and (2) surface protein mediators of platelet activation.

Perhaps the most thoroughly studied $S$. aureus toxin or secretory factor interacting with platelet function is alpha $(\alpha)$ toxin. The expression of this exotoxin is accessory-gene regulon (agr)-regulated, and targets platelets as well as other host cells. The toxin is believed to interact with the cell membrane of platelets, erythrocytes, and even some leukocytes, inducing injury and ultimately cellular lysis. Notably, Bayer et al. [96] found a paradoxical relationship between $S$. aureus $\alpha$-toxin expression and virulence in vivo, specifically pertaining to platelet interactions. These authors evaluated the impact of $\alpha$-toxin in experimental endocarditis in vivo using isogenic strains differing in expression of functional versus mutant forms of $\alpha$-toxin. In vitro, the parental $\alpha$-toxin induced platelet lysis and secretion of platelet microbicidal proteins (PMPs; see below) active against $S$. aureus. In experimental endocarditis, the $S$. aureus strains producing either minimal $\alpha$-toxin or non-functional $\alpha$-toxin were significantly less virulent in vivo than wild-type strains. Paradoxically, an isogenic strain constructed to overexpress $\alpha$-toxin was also significantly less virulent than its parental counterpart in this animal model. Moreover, increased $\alpha$-toxin expression correlated with greater PMP release by exposed platelets. Together, these outcomes indicated that expression of excessive $\alpha$-toxin leads to increased PMP release secondary to either platelet secretion or lysis, thus increasing antistaphylococcal platelet responses and reduced virulence in experimental endocarditis. This phenomenon is referred to as a "Goldilocks Effect" in S. aureus-host relationships.

Regarding non-soluble mediators, most studies focusing on interactions of platelets with S. aureus have focused on surface proteins expressed by the pathogen. In early experiments, Hawiger et al. [97] demonstrated that $S$. aureus triggers platelet morphogenesis, aggregation, and degranulation in a pathway involving $S$. aureus protein A, host $\mathrm{IgG}$, and platelet $\mathrm{Fc}$ receptors. Considerable work since then has revealed that this organism employs several factors to interact with platelets when it is advantageous to do so. For example, S. aureus surface proteins that mediate direct or indirect platelet interactions include clumping factors A and B (ClfA/ClfB), fibronectin-binding proteins A and B $(F n b p A / F n p b B)$, protein A $(S p a)$, serine-aspartaterepeat protein $\mathrm{E}(S d r E)$, serine-rich adhesin for platelets $(S r a P)$, extracellular fibrinogen-binding protein $(E f b)$, and other molecules. A meritorious review of these $S$. aureus surface proteins, and homologous factors of other pathogens has been compiled by Fitzgerald et al. [10]. Hence, the following comments focus on fundamental themes regarding such surface proteins and recent studies of their platelet interactions. 
In complementary studies, Sullam et al., Yeaman et al., and Bayer et al. used classical aggregometry and multicolor flow cytometry to investigate the molecular and cellular interactions between staphylococci and platelets [98-100]. These studies revealed that staphylococci adhere directly to human or rabbit platelets in vitro, in the absence of plasma. Notably, the $S$. aureus-to-platelet ratio directly influences the extent and velocity with which platelet aggregation follows after initial contact [99]. Additionally, rapid adherence to platelets occurs via saturable and reversible kinetics that are indicative of receptor-ligand interactions. As multiple $S$. aureus surface proteins can mediate platelet interactions, such findings suggest that each receptor-ligand interaction may occur independently as well as cooperatively. Recently, Siboo et al. [101] characterized a serine-rich protein, SraP, that mediates adhesion of $S$. aureus to platelets. Moreover, a mutant deficient in $\operatorname{SraP}$ has a reduced virulence phenotype in rabbit models of infective endocarditis. This protein is $227 \mathrm{kDa}$ and, similar to its streptococcal homolog $G s p B$, is predicted to contain unusual $\mathrm{N}$-terminal signal sequences, two serine-rich repeat domains, and a C-terminal motif likely required for cell wall anchoring (LPDTG; also see below).

In related studies, Niemann et al. [102] reported that platelet quality influences $S$. aureus-platelet interactions. In their investigation, platelets obtained from patients with specific inherited deficiencies in platelet granule contents (e.g., $\alpha-\delta$ storage pool disease or Gray platelet syndrome) were assessed for interactions with $S$. aureus. Interestingly, CD36 (thrombospondin receptor), GPIIb/IIIa (a major platelet integrin receptor), and CD62 (P-selectin) did not play significant roles as receptors for $S$. aureus. Further, platelet activation by ADP did not promote $S$. aureus adhesion, although platelets were found to be bound by fibrinogen. On the contrary, soluble fibrin (but not fibrinogen), clumping factor A and thrombospondin-1 increased platelet binding to $S$. aureus. Thus, these latter molecules likely act as bridging matrices that promote $S$. aureusplatelet interactions.

Such findings highlight an emerging theme increasingly evident in interactions between staphylococci and platelets: S. aureus and other staphylococci exploit plasma cofactors to facilitate interaction with platelets when advantageous, or limit interactions to subvert platelet antimicrobial responses. For example, $S$. aureus interacts with vascular endothelium and platelets via fibrinogen bridging [103, 104]. Bayer et al. [100] found that $S$. aureus can induce aggregation of rabbit platelets via a fibrinogen-dependent mechanism independent of GPIIb/IIIa. Moreover, fibronectin is not significantly involved in staphylococcal adhesion to quiescent platelets. In contrast, fibronectin does appear to faciliate $S$. aureus interactions with activated platelet-fibrin clots or stimulated endothelium [105]. Likewise, Hermann et al. [106] found that S. aureus exploits thrombospondin to adhere to activated platelets and extracellular matrices. Loughman et al. [107] further demonstrated that cognate immunoglobulin directed against clumping factor (ClfA) can modulate $S$. aureusplatelet adherence. Alternatively, $S$. aureus has been shown to bind to platelets through mechanisms involving protein $\mathrm{A}$ and the platelet $\mathrm{C} 1 \mathrm{q}$ complement receptor, $\mathrm{gC} 1 \mathrm{qR} / \mathrm{p} 33$ [108]. As $\mathrm{gC} 1 \mathrm{qR} / \mathrm{p} 33$ is expressed upon activated but not quiescent platelets, $S$. aureus may specifically exploit adhesion to activated platelets. Such examples highlight the emerging theme that $S$. aureus and platelets interact directly and indirectly through multiple soluble and cellassociated bridging ligands.

Other new evidence indicates that the serine-aspartaterepeat protein $\mathrm{G}(\mathrm{SdrG})$, a fibrinogen-binding protein present in a majority of clinical S. epidermidis isolates, is sufficient to enable this organism to adhere to and aggregate platelets [110]. Brennan et al. employed surrogate genetics to shown that Lactococcus lactis expressing SdrG induces platelet aggregation in a manner dependent on both fibrinogen and $\operatorname{IgG}$, and on the platelet $\operatorname{IgG}$ receptor Fc $\gamma$ RIIa. Pre-exposure of SdrG-expressing L. lactis to $\beta$-chain fibrinopeptide reduced platelet aggregation; substantiating the interpretation that fibrinogen is a bridging intermediate. Interestingly, in their studies, such aggregation was inhibitable by GPIIb/IIIa antagonists as well as by aspirin.

Lastly, a new role for $S$. aureus-platelet interactions has recently been put forth. Youssefian et al. [109] reported that platelets can actively phagocytose Staphylococcus aureus. Internalization of the organism corresponded to morphological transition consistent with platelet activation. In turn, platelet activation recursively enhanced $S$. aureus internalization. Although these findings support the emerging view that platelets are active host defense cells, it remains to be seen whether platelet antimicrobial responses are related to internalization, or result from degranulation of microbicidal proteins to target extracellular pathogens (see below).

Streptococcal interactions with platelets

Pathogenic members of the genus Streptococcus are typically viewed as human commensal organisms that can gain entry to the bloodstream. Until recently, streptococci (e.g., Streptococcus sanguis) were viewed as the most common etiologic agents of infective endocarditis (IE); S. aureus has now assumed that role. Nonetheless, the fact that most humans experience transient streptococcal bacteremia regularly without the onset of endovascular infections or infective endocarditis suggests there are 
highly efficacious host defense interactions between platelets and streptococci. In this respect, a substantial body of literature has been published investigating the ability of various streptococcal species to interact with human platelets. The following section illustrates comparative themes and recent insights into this relationship.

Traditionally, streptococci have been found to interact with platelets through a variety of mechanisms and molecular intermediates. Herzberg et al. reported that certain viridans streptococci such as Streptococcus sanguis adhere directly to the platelet surface via a $150-\mathrm{kDa}$ twodomain adhesin [70, 71, 111]. Zimmerman et al. [112] showed that St. pneumoniae aggregates platelets only in the presence of cognate anti-pneumococcal antibody in vitro. As in S. aureus, Ford et al. [113] demonstrated that St. sanguis aggregates platelets through a fibrinogen pathway involving platelet integrin GPIIb/IIIa receptor. Similarly, platelet aggregation and degranulation prompted by St. pyogenes can be mediated by fibrinogen [114], while Johnson and Bowie [115] reported that that some group C streptococci indirectly with platelets through the von Willebrand factor.

New evidence derived from contemporary methods in microbial genetics and flow cytometry have greatly advanced our understanding of streptococcal-platelet interactions. As seen in S. aureus, such findings illustrate how streptococci interact with platelets directly and indirectly. For example, although St. gordonii has been known to interact with platelets, new insights are emerging indicating that very specific intermediaries result in its adherence to and activation of platelets. Using surrogate genetics, Kerrigan et al. [116] demonstrated that overexpression of St. gordonii $\mathrm{SspA}$ or SspB (antigen I/II family proteins) in null Lactococcus lactis enabled the latter organism to induce platelet aggregation, but not adhere to platelets. This finding suggests that the Ssp-family proteins may mediate soluble activation of platelets. In contrast, St. gordonii Hsa protein (a homolog of GspB) facilitated platelet adhesion. Thus, St. gordonii appears to have distinct molecular mechanisms for platelet adhesion and platelet aggregation. Given its ability to cause IE in humans, it is intriguing to speculate that regulated expression of these or other platelet interaction molecules may determine how St. gordonii or other streptococcal pathogenesis interact with platelets to exploit these host cells, or avoid platelets if it is advantageous to subvert antimicrobial responses of these cells.

Perhaps the most novel insights into streptococcalplatelet interactions in recent years have emerged from important studies performed in the Sullam laboratory. Prior studies by Sullam et al. found that viridans group streptococci aggregate human platelets via direct platelet binding, as well as through plasma cofactors [68, 98, 117]. For example, the aggregation of human platelets by some streptococci requires organism-specific IgG, which presumably interacts with the platelet $40-\mathrm{kDa}$ Fc $\gamma$ RII surface receptor [117]. Ensuing studies by Bensing et al. [118] identified two genetic loci in St. mitis that appeared to mediate binding to human platelets in vitro. These discoveries suggest that interactions between streptococci and platelets occurs via specific receptor-ligand interactions. More recently, this group demonstrated that two plateletbinding adhesins from St. mitis-PblA and PblB-are encoded as a results of lysogenic prophage integration [119]. Interestingly, translocation of these proteins to the bacterial cell wall for surface display requires holin or lysin gene expression. The export of these proteins apparently requires membrane permeabilization, enabling anchoring to cell wall choline rather than conventional anchoring motifs. More importantly, loss of PblA and PblB expression yields decreased platelet binding in vitro, and reduced virulence in experimental IE. More recent reports from this group indicate that $\mathrm{PblA}$ and $\mathrm{PblB}$ proteins target $\alpha 2-8$-linked sialic acids on ganglioside GD3 for adhesion to human platelets [120]. Thus, this body of work reveals how streptococci appear to interact with human platelets through highly sophisticated molecular and cellular determinants.

In parallel to their studies above, the Sullam laboratory investigated the role of cell surface glycoprotein GspB in St. gordonii adherence to platelets [121]. Isogenic strains of St. gordonii M99 with or without gspB expression were evaluated in models of infection in rats, independently and in strain competition studies. When infected independently, cardiac vegetation, kidney, and spleen tissues had significantly lower densities of the null mutant as compared with the wild-type strain. Further, in competition studies in which both strains were co-infected, the wild-type strain achieved significant CFU densities in these tissues, while the gspB mutant was not detectable. These findings strongly suggest that GspB confers an important platelet binding function to this organism that may be important to virulence in vascular pathogenesis. It is also noteworthy that prior studies by this laboratory demonstrated that glycosylation of GspB is mediated in part by Gly and Nss proteins encoded in the secY2A2 locus [122]. Complementary genetic and protein analyses revealed that Gly, Nss, Gtf, and Orf4 are involved in the intracellular glycosylation and solubility of GspB. Thus, extracellular access and glycosylation state appear to be key to the ability of GspB to promote adhesion of St. gordonii to human platelets.

Bacteria must circumvent or subvert the significant antimicrobial mechanisms of platelets to exploit these cells in virulence strategies. Alternatively, it is possible that profusive platelet responses to streptococci may contribute 
to adverse outcomes not necessarily related to virulence. For example, Ohba et al. [123] demonstrated in mice that St. intermedium or St. constellatus injected intravenously triggered platelet-mediated responses mirroring septic shock. In animals primed with muramyldipeptide, whole organisms introduced into the vascular compartment caused a rapid anaphylactoid-like shock response. However, in non-primed animals, little or no sign of shock was observed. Interestingly, the cardinal signs of shock response were preceded by platelet degranulation and 5-hydroxytryptamine (5HT) secretion, as well as complement fixation yielding activated C5. The septic-shock-like paradigm was mitigated by a complement-C5 inhibitor. Collectively, these results suggest that platelets respond to streptococci by activating host defense mechanisms including degranulation and complement fixation. However, certain pathogens may hyperstimulate platelets such that activation, degranulation, complement fixation, or other immune responses occur to an excessive degree that results in non-optimal host outcomes.

The studies highlighted above illustrate the emerging theme that distinct streptococcal species and phenotypes vary in interactions with human platelets. It is highly likely that distinct pathogens have co-evolved with hosts so as to optimize their interactions with platelets for fitness advantages. For example, early studies demonstrated that St. pyogenes can prompt platelet aggregation perhaps by a molecular mimic of collagen [124]. In contrast, St. pneumoniae appears to optimally induce aggregation by way of an antibody-dependent mechanism [112]. In contrast, St. agalactiae expresses a fibrinogen-binding protein known as FbsA that confers adhesion and aggregation of platelets mediated by fibrinogen and IgG [125]. These and other theme-and-variation examples illustrate how pathogens such as streptococci or staphylococci that often encounter platelets and other host defenses in the bloodstream have necessarily evolved diverse mechanisms to interact with platelets. It is conceivable these some adaptations may provide advantages to enable pathogens to circumvent or subvert platelet-mediated host defense mechanisms.

Gram-negative pathogen interactions with platelets

Relatively little is known about platelet interactions with Gram-negative pathogens as compared with Gram-positive counterparts. Other reviews offer comprehensive perspectives of such comparisons [1, 6-10]. Here, the following discussion highlights the current view that Gram-negative pathogens capable of entering the bloodstream have important interactions with platelets that likely contribute to the difference between virulence and host defense.
One of the best examples of this theme can be considered from studies assessing interactions between platelets and Pseudomonas aeruginosa or Yersinia species. Coutinho et al. [126] reported that the major phospholipase C from $P$. aeruginosa caused platelet aggregation in a dosedependent manner. Interestingly, the use of heat-denatured enzyme, or nitrophenol-phosphoryl-choline (inactive substrate of phospholipase $\mathrm{C}$ ), revealed that enzymatic function of phospholipase $\mathrm{C}$ was required for platelet activation. Furthermore, ADP, epinephrine, collagen, or ristocetin were unable to inhibit phopholipase $\mathrm{C}$ activation of platelets, and lack of inhibition by aspirin or nordihydroguairetic acid suggested that the mechanism was independent of prostaglandin or lipooxygenase pathways.

In recent studies, Machado et al. [127] examined the role of $P$. aeruginosa phospholipase A2 on platelet activation in a mouse model of infection. Pseudomonal phospholipase A2 is encoded by the ExoU gene, and is a well-established cytotoxin. In a pneumosepsis model, mice instilled intratracheally with ExoU-producing $P$. aeruginosa caused a significantly higher mortality rate, reduced leukocyte concentration, higher platelet concentration, and higher hematocrit than animals infected with the exoU null mutant. Moreover, platelets from mice infected with the wild-type strain were significantly more activated than the null mutant, as indicated by P-selectin expression, plateletderived microparticle detection, and immunoassay detection of thromboxane A2 (TXA2). Lung and kidney histopathology of wild-type-infected mice revealed thrombus formation that was absent in null-infected animals. Based on these observations, it appears that activation and thrombus formation in response to phospholipase A2-producing strains of $P$. aeruginosa may contribute to pathogenesis.

Yersinia species also appear to interact with platelets in ways that are likely to influence to the consequences of pathogenesis versus host defense. Recent studies by Shepel et al. [128] examined interactions of $Y$. entercolitica and $Y$. pseudotuberculosis with platelets in vitro. From prior studies, $Y$. pseudotuberculosis is known to be capable of entering platelets and inducing platelet aggregation via a mechanism involving expression of the inv invasin gene. In the recent studies, both Yersinia strains were engineered to express green fluorescent protein to enable real-time assessment of interaction with platelets by flow cytometry. While both strains adhered to platelets, only $Y$. pseudotuberculosis caused platelet activation and aggregation. Moreover, $Y$. enterocolitica bearing virulence plasmid pYV+ interacted with platelets, while a pYVstrain did not. Transmission electron microscopy revealed that $Y$. pseudotuberculosis expressing the inv gene was able to invade platelets. However, $Y$. enterocolitica or 
$Y$. pseudotuberculosis devoid of the inv gene remained on the extracellular surface of platelets.

An interesting recent study, Bhat et al. [129] analyzed potential correlates of organism-specific infection, platelet response, and thrombocytopenia in low birth weight neonates with sepsis. Over a 5-year period, very low birth weight neonates $(<1,500 \mathrm{~g})$ in a level-three intensive care unit were prospectively evaluated for sepsis. Gram-positive sepsis occurred in $20 \%$ of these patients, Gram-negative in $71 \%$, and fungal sepsis in $8.6 \%$. Thrombocytopenia was observed in $67 \%$ of patients overall. The frequency and duration of thrombocytopenia were significantly greater in Gram-negative and fungal infections; persistent bacteremia, multiorgan failure, and mortality were significantly greater in thrombocytopenic patients. Importantly, multiorgan failure and mortality were directly correlated with duration of thrombocytopenia. On multiple logistic regression analysis, the worst prognostic indicators were a severe drop in platelet count at onset of sepsis, a low platelet nadir, prolonged duration of thrombocytopenia, and need for platelet transfusion. Given the majority of poor outcomes correlating with Gram-negative infections, molecular interactions of platelets with such organisms, and the virulence versus host defense consequences of these interactions, remain areas that merit considerable focused research.

\section{Platelet mechanisms of host defense against pathogenic bacteria}

\section{Chronologic overview}

Historically, platelets have been viewed as contributing to microbial pathogenesis. However, it is now evident that platelets have explicit structures and functions that contribute significantly to host defense against infection. Over the past decade, contemporary techniques in host-pathogen relationships, protein chemistry, and molecular biology have been applied to identify and define the molecular effectors and mechanisms of platelet host defenses. Platelets interact rapidly, directly, and specifically with bacterial pathogens, liberate an array of direct antimicrobial molecules, and shape adaptive immune responses. Detailed reviews of such platelet mechanisms of molecular and cellular antimicrobial defense have been reviewed elsewhere [1, 6-10].

Perhaps the earliest mention of platelet antimicrobial function was in 1887, when Fodor reported a heat-stable bactericidal capacity of serum, termed $\beta$-lysin, distinct from heat-labile or $\alpha$-lysin complement proteins [130]. Later, Gengou demonstrated that $\beta$-lysin bactericidal activity of serum derived from cells involved coagulation, and was independent of complement [131]. In 1938, Tocantins reviewed studies that suggested possible immune functions of platelets [5]. Subsequent studies by Hirsch demonstrated that platelets, not classical leukocytes, conferred bactericidal activity to rabbit serum [132]. Eventually, many other noted investigators, including Jago and Jacox [133], Weksler [134], Kahn et al. [135], Czuprynski and Balish [78], and Miragliotta et al. [136] affirmed that platelets exert in vitro bacteriostatic and/or bactericidal effects versus many pathogens, including Bacillus, Staphylococcus, Listeria, Salmonella, and many other organisms.

In subsequent studies, numerous investigators studied platelet-specific molecule(s) that might be associated with the antimicrobial action of serum [133, 137-144]. Among the earliest of these reports, Myrvik [140] demonstrated that two platelet-derived serum factors were responsible for killing of Bacillus subtilis. Jago and Jacox [133] and Myrvik and Leake [141] confirmed these findings. Later, Donaldson et al.[142], Johnson et al. [143], and other groups isolated putative $\beta$-lysins from rabbit serum that exerted S. aureus- or B. subtilis-specific killing. In parallel, Weksler and Nachman [144] isolated two cationic proteins from platelets with molecular masses of 10 and $40 \mathrm{kDa}$ that were bactericidal in vitro versus $B$. subtilis and $S$. aureus strains, respectively. In each of the above studies, the platelet antimicrobial effector molecules were identified as being small and cationic, with masses ranging from 6 to $40 \mathrm{kDa}$. Tew et al. [145] found that $\beta$-lysin proteins were released from rabbit platelets by stimulation with thrombin, establishing a potential link between tissue injury and platelet liberation of host defense effectors. Likewise, Dankert et al. [146, 147] also suggested that platelets release platelet-associated bactericidal substances following thrombin stimulation. Darveau et al. [148] identified peptide fragments of human platelet factor-4 with antimicrobial activity in combination with antibiotics against certain Gram-negative bacteria.

\section{Platelet microbicidal proteins and kinocidins}

In recent years, the molecular effectors of platelet antimicrobial response have been the topic of intensive investigation. By convention, the term platelet microbicidal proteins (PMPs) is used to include PMPs, thrombininduced PMPs (tPMPs), and derivatives thereof termed thrombocidins. Importantly, a subset of PMPs have been discovered to be classical chemokines that have direct microbicidal activity. These polypeptides are termed kinocidins, reflecting their dual chemokine and microbicidal effector functions [149]. Important investigations by Cole et al. [150], Yang et al. [151], and others have subsequently reinforced this discovery. Detailed structures and mechanisms of PMPs and kinocidins are available in other reports 
[152-163]. However, it is helpful to emphasize herein that PMPs and kinocidins differ in several important respects from classical antimicrobial peptides such as defensins.

The family of PMPs and kinocidins can be found in human and other mammalian platelets [1, 7, 152-163]. Two predominant PMPs (tPMPs 1 and 2) are liberated from platelets upon thrombin stimulation [154-156]. These, like PMPs and kinocidins, exist as native species that appear to undergo proteolytic cleavage in contexts of infection. For example, Yount et al. [156, 157] and Yeaman et al. [157-159] have shown that PMPs are cleaved into autonomous but complementary functional domains by contextrelevant proteases such as thrombin. Likewise, Anderson et al. [164] have confirmed these previous findings that fragments of mammalian platelet factor-4 and related molecules can also have antimicrobial efficacy. The fact that thrombin is generated at sites of vascular infection, and is a strong inducer of platelet degranulation, illustrate how PMP and kinocidin release is coordinated with response to endovascular host defense [159]. Mass spectroscopy has demonstrated that PMPs and kinocidins range in size from approximately 6.0 to $9.0 \mathrm{kDa}[1,158,181]$. Cloning and amino acid analyses affirm these molecules to have a net cationic charge, mediated by an enrichment of basic residues lysine and arginine. Molecular mass, sequence, lysine content, and other features distinguish PMPs and kinocidins from classical defensins [1, 154, 158] overall. However, recent discoveries have identified a multidimensional signature - termed the $\gamma$-core-that unifies these and other host defense molecules by way of physicochemical themes as distributed across their 3D shape [161, 163]. To summarize a considerable body of recent literature, PMPs, kinocidins, fragments and synthetic congeners thereof have repeatedly been shown to exert strong in vitro, ex vivo, and in vivo efficacy against Gram-positive and Gram-negative bacteria and fungi [1, 158, 165]. Of note, Azizi et al. [166] and Bayer et al. [96] have also shown that specific pathogens or purified staphylococcal $\alpha$-toxin prompt specific PMP or kinocidin release profiles from platelets in vitro. These and other aspects of PMPs and kinocidins have been reviewed elsewhere [1, 158]. Thus, the remainder of this report focuses on key themes and potential correlates of these molecular effectors of host defense against bacterial infection.

PMPs and kinocidins derive from distinct genetic lineages

The repertoire of PMPs and kinocidins is now known to represent multiple molecular species representing several genetic lineages. Tang et al. [152] first isolated and identified antimicrobial peptides from human platelets that are homologous to those in other mammals. Today, an array of host defense effector peptides is known to be liberated from human platelets upon thrombin stimulation. The array of PMPs and platelet kinocidin molecules includes: platelet factor-4 (PF4), platelet basic protein (PBP) and its proteolytic derivatives, connective tissue-activating peptide-3 (CTAP-3) and neutrophil-activating peptide-2 (NAP-2), RANTES ("released upon activation, normal $\mathrm{T}$ cell expressed and secreted"), thymosin- $\beta-4$ (T $\beta-4)$, and fibrinopeptides A and B (FP-A and FP-B) [152, 153]. Importantly, these antimicrobial effector proteins arise from five genetically-distinct lineages in humans and other mammals: (1) PF-4 and variants; (2) PBP and its proteolytic derivatives CTAP-3 and NAP-2; (3) RANTES; (4) $\mathrm{T} \beta-4$; and (5) fibrinopeptides. Therefore, potential defects or deficiencies in one given lineage are not likely to negatively impact others. Such redundancy may have played an important role in evolution of mammalian immunity against bacterial and other microbial pathogens.

Kinocidins can be classified relative to their chemokine nomenclature. For example, PF-4, PBP, CTAP-3, and NAP-2 are $\alpha$-kinocidins, as they possess CXC-chemokine motifs. In contrast, RANTES is a $\beta$-kinocidin, containing a $\mathrm{CC}$-chemokine motif. The direct antimicrobial activities of these proteins were initially identified by Tang et al. [152] and Yeaman et al. [155]. Krijgsveld et al. [167] subsequently suggested that carboxy-terminal di-amino acid truncated versions of NAP-2 or CTAP-3 also exerted antimicrobial activity in vitro. Native PMPs and kinocidins can be further processed in the context of infection or tissue injury after liberation from platelets. Thrombin (a serine protease), platelet-derived proteases, and proteases activated by tissue injury, phagocytes (e.g., cathepsin $\mathrm{G}$ ), or inflammation (e.g., plasmin) may process native PMPs and kinocidins, generating multiple antimicrobial peptide subspecies [1, 157, 161]. Recently, molecular studies of structure-activity relationships among PMPs and kinocidins have discovered fascinating new insights into the likely roles of these molecules in optimizing host defense [156, 161, 162]. For example, amino acid sequencing and mass spectrometry have demonstrated distinct N-terminal polymorphism variants of rabbit PMP1 from unactivated versus thrombin-stimulated platelets, respectively, that arise from a single common PMP-1 propeptide [156]. Alternatively, PMPs and kinocidins respond to microbial virulence factors such as proteases by deploying domains with optimized antimicrobial efficacy versus cognate pathogens in contexts of infection [1, 157]. Yeaman et al. invented a novel platform of anti-infective agents that integrate the architecture and processing of PMP and kinocidin proteins which have autonomous yet complementary antimicrobial effector domains that are deployed via disassembly in context [157, 168]. Supporting this concept, Sieprawska-Lupa et al. [169] have 
also shown that Staphylococcus aureus exoenzymes aureolysin and V8 protease cleave the antimicrobial peptide LL-37. Finally, discoveries of structural, functional, and evolutionary relationships among host defense peptides, classical toxins, and like molecules now afford a new understanding of host defenses, and opportunities to develop anti-infective peptides with minimal host cytotoxicity [170].

It is now known that monocytes have been shown to express PMPs and kinocidins with antimicrobial activity. For example, the PMP and $\alpha$-kinocidin platelet basic protein (PBP) is also expressed in human monocytes [171]. Most recently, studies have demonstrated that exposure of human monocytes to bacteria or LPS evokes a significant increase in expression of monocyte PBP and derivatives thereof [171]. This response involves activation of proteinase-activated receptors (PARs) by thrombin or synthetic peptide ligands such as SFLLRN. Importantly, two bactericidal derivatives of PBP were seen to enter phagolysosomes, ostensibly to act therein to aid in intracellular inactivation and killing of pathogens. These findings reinforce the prior discoveries that PBP and other PMPs or kinocidins are multifunctional antimicrobial effector proteins as discussed below.

\section{Kinocidins integrate complementary antimicrobial} defense systems

Kinocidins orchestrate key events that provide innate antiinfective defenses in settings of infection, and bridge adaptive immunity as optimized to control specific pathogens. Kinocidins have well-established chemotactic functions known to recruit and activate antimicrobial mechanisms of leukocytes and lymphocytes. Yeaman and Yount have recently described how these molecules are optimized to defend against infection of distinct physiologic and anatomic contexts, and in dynamic contexts, as they change over time in response to infection [161, 163, 170]. This paradigm of immunocoordination is termed the AEGIS model of host defense effector peptides: Archetype Effectors Governing Immune Syntax [157]. This model derives from another recent advance in understanding host defense immunobiology-antimicrobial peptide immunorelativity [157, 163]. This concept is a functional concatenation of molecular regulation and physicochemical optimization of host defense peptide structures and functions in particular anatomic or physiologic context to defend against cognate pathogens. Thus, PMPs, kinocidins, and leukocytes recursively potentiate one another in host defense against infection. The AEGIS model of immunocoordination as applied to kinocidins is exemplified through an integration of multiple lines of evidence.

\section{Modular architecture}

Kinocidins exhibit modular functional domains that can be deployed to act autonomously to facilitate cooperative, synergistic host defense functions. For example, kinocidins effect immediate and direct antimicrobial actions, recruit leukocytes to sites of infection, and potentiate the antimicrobial mechanisms of these cells [1, 6-9]. Excellent studies by the Gallo laboratory [172] have also suggested that certain human cathelicidins also encode multifunctional capacity for host defense.

\section{Immune syntax}

The coordinated deployment of multiple and complementary defense mechanisms such as those encoded in kinocidins in sequence, place, and time to optimize host defense has been termed immune syntax. This process is believed to occur through a corresponding series of events [157]: (1) hallmark signals of infection evoke host cell release of kinocidins in cognate physiologic, anatomic, and microbiologic contexts in response to microbial signals or tissue injury; (2) affinity for microbial cells then concentrates native kinocidins, and their antimicrobial domains begin to exert immediate antimicrobial activity; (3) proteolytic cleavage yields further diversity of functions, including protease inhibition to extend peptide lifespan; (4) diffusion of kinocidin chemotactic domains establishes gradients for leukocyte chemonavigation, and potentiates their antimicrobial mechanisms en route; (5) in turn, predecoration by kinocidin opsonic domains promotes pathogen phagocytosis by recruited leukocytes, and in turn potentiate leukocyte; and (6) in the restricted context of the acidic phagolysosome, certain kinocidins or domains thereof have enhanced microbicidal properties. Thus, through immune syntax, kinocidins contribute to host defense through coordinated deployment of direct and indirect antimicrobial functions as optimized to context.

\section{Molecular mechanisms of PMP and kinocidin response}

Platelets can be viewed as vehicles, which sense molecular signals of tissue infection or injury and respond by delivering anti-infective molecules and wound-healing factors. Thus, the protective roles of PMPs and kinocidins rely on platelet detection of warning signals, and prompt mobilization and release of these molecules to act in innate host defense. As detailed above, PMPs and kinocidins are released from platelets upon exposure to infection-relevant stimuli, such as thrombin, S. aureus $\alpha$-toxin, or microbial pathogens, including viridans group streptococci, $S$. aureus, and C. albicans. Recent studies have provided new insights into the molecular mechanisms through which 
platelets release PMPs and kinocidins in response to pathogens. Trier et al. [173] demonstrated that platelets release PMPs and kinocidins through specific molecular pathways following interaction with $S$. aureus. At platelet$S$. aureus ratios of 10:1 or greater, platelet activation occurred and resulted in release of staphylocidal levels of PMPs and kinocidins. Apyrase (ADP degradation), suramin (a general P2 receptor antagonist), pyridoxal 5-phosphonucleotide derivative (a specific $\mathrm{P}_{2} \mathrm{X}_{1}$ antagonist), and cangrelor (a specific $\mathrm{P}_{2} \mathrm{Y}_{12}$ antagonist) mitigated the staphylocidal response against both strains, correlating with reduced levels of PMP and PK release. Specific inhibition occurred in the presence and absence of homologous plasma. In contrast, inhibition of thromboxane A2, COX-1 or -2 , or phospholipase $\mathrm{C}$ pathways, or hindrance of surface adhesion receptors, did not impede anti-S. aureus responses. Taken together, this pattern of data suggests a multifactorial platelet anti-S. aureus response mechanism involving: (1) platelet activation in response to $S$. aureus; (2) ensuing degranulation of PMPs, kinocidins, and ADP/ATP; (3) ADP activation of $\mathrm{P} 2 \mathrm{X}_{1} / \mathrm{P} 2 \mathrm{Y}_{12}$ receptors on adjacent platelets; and (4) recursive amplification of PMP and kinocidin release from successive platelets. Thus, PMP and kinocidin response to S. aureus occurs via an active, rapid and direct mechanism, amplified through autocrine pathways in which platelet ADP/ATP release prompts successive waves of platelet degranulation via the platelet $\mathrm{P} 2 \mathrm{X}$ and $\mathrm{P} 2 \mathrm{Y}_{12}$ adenosine nucleotide receptor array (Fig. 1). Sharma et al. showed that outer membrane constituents of Porphyromonas

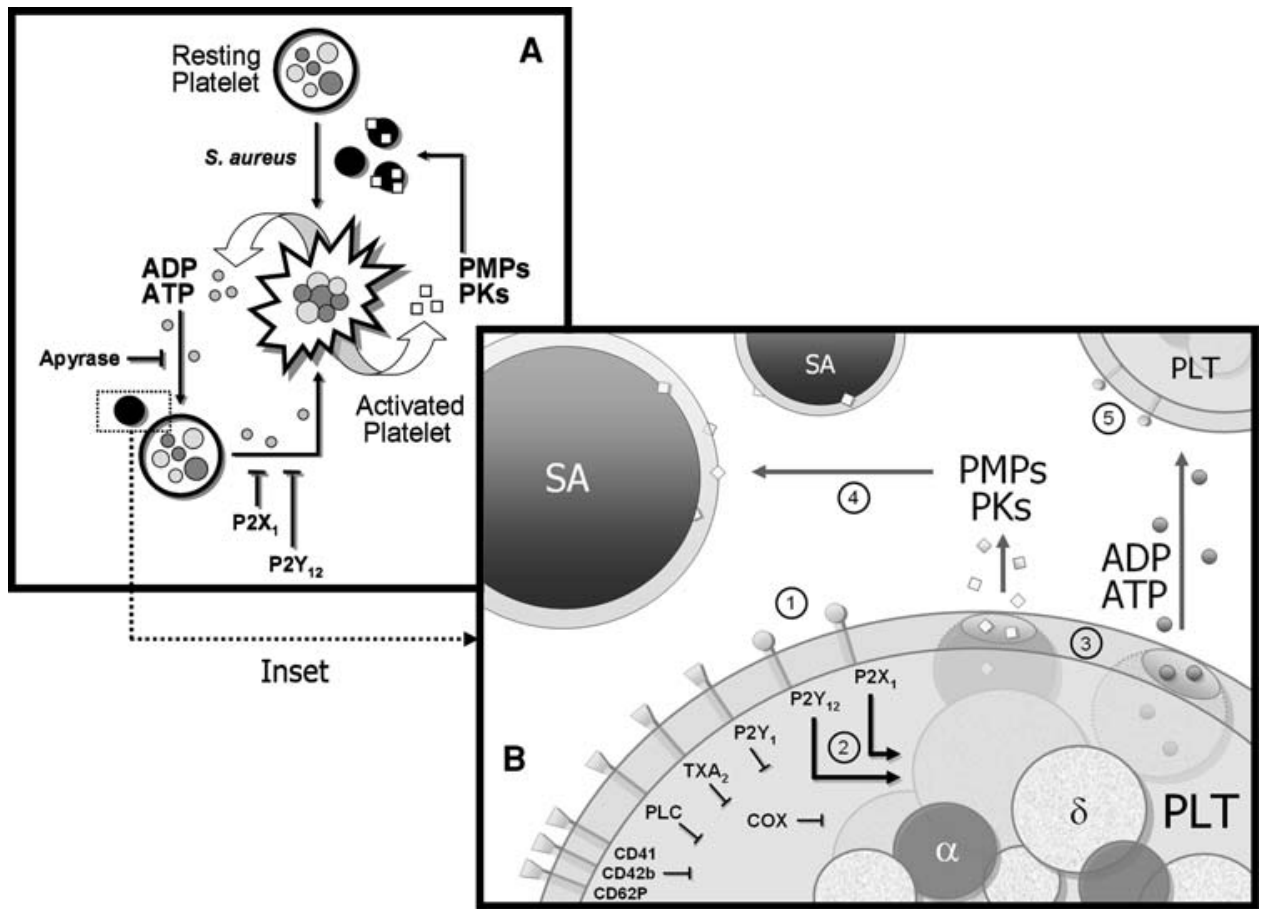

Fig. 1 Model of platelet interactions with Staphylococcus aureus. Based upon recent evidence, the model illustrates how platelets may sense and respond via parallel pathways that promote anti-staphylococcal host defense. a On the cellular level, interactions with S. aureus evoke: (1) platelet activation via specific receptors; (2) liberation and processing of PMPs and PKs which exert direct microbicidal effects, and (3) secretion of adenosine nucleotides (ADP/ATP) triggering a recursive cascade for activation of adjacent platelets. Note that inhibitors of the purinergic pathway of activation preclude anti-staphylococcal responses. b On the molecular level, specific sense and response pathway components are illustrated. Purinergic agonists such as ADP are known stimulants of strong platelet activation. Thus, degradation of extracellular ADP by apyrase $(A P Y)$ or the inhibition of $\mathrm{P} 2 \mathrm{X}$ or $\mathrm{P}_{2} \mathrm{Y}_{12}$ adenosine nucleotide receptors by suramin (SUR; general $\mathrm{P} 2$ inhibitor), pyridoxal-5'phosphonucleotide derivative ( $P N D$; high-affinity $\mathrm{P}_{2} \mathrm{X}_{1}$ inhibitor), or cangrelor $\left(C N G\right.$; high-affinity $\mathrm{P}_{2} \mathrm{Y}_{12}$ inhibitor) specifically prevents platelet $(P L T)$ sense and response activation for staphylocidal efficacy. In contrast, antagonism of the $\mathrm{P}_{2} \mathrm{Y}_{1}$, phospholipase $\mathrm{C}$ (PLC), thromboxane $\mathrm{A}_{2}\left(T X A_{2}\right)$, or cyclooxygenase (COX) pathways, or inhibition of the CD41, CD42b, or CD62P platelet adhesin receptors do not impede the sense and response activation of platelets versus $S$. aureus. Thus, the antistaphylococcal efficacy of platelets involves a self-amplifying, recursive sense and response mechanism: (1) direct or indirect interactions of platelets and S. aureus (SA); (2) platelet activation, via autocrine or intercrine $\mathrm{P}_{2} \mathrm{X}_{1}$ or $\mathrm{P} 2 \mathrm{Y}_{12}$ receptormediated signal transduction prompting granule mobilization; (3) degranulation and liberation of ADP/ATP from $\delta$-granules; (4) deployment of direct antimicrobial effector molecules (PMPs and PKs) from $\alpha$-granules; and (5) adenosine nucleotide-mediated activation of adjacent platelets, with the ensuing amplification of antimicrobial responses. Such interactions are likely influenced by platelet-to-S. aureus ratios. In this respect, staphylocidal efficacy appears to involve a threshold platelet ratio to generate and sustain an intercrine platelet cascade required to achieve PMP/PK concentrations for staphylocidal efficacy. Adapted from [173] 
gingivalis activate murine platelet aggregation and degranulation through similar pathways [174].

Antibacterial efficacy of platelets, PMPs, and kinocidins

The specific antimicrobial mechanisms of PMP and kinocidin actions against bacterial or other pathogens are detailed in other publications (e.g., $[1,175])$. In brief, these peptides are rapidly microbicidal, with mechanisms that are distinguishable from classical antimicrobial peptides. For example, the staphylocidal mechanisms of PMPs and kinocidins against $S$. aureus differ from those of human defensin NP-1 (hNP-1) in several important respects: involvement of membrane potential $(\Delta \psi)$, permeabilization, and bactericidal kinetics. Therefore, the following discussion highlights the novel and relevant themes in platelet, PMP, and kinocidin antibacterial response.

\section{Efficacy of PMPs and kinocidins in vitro}

A substantial body of literature now exists demonstrating that PMPs and kinocidins effect direct, rapid, and potent efficacy against many microbial pathogens in vitro. For example, PMPs and kinocidins exert potent and synergistic in vitro microbicidal activities against Bacillus subtilis, S. aureus, S. epidermidis, E. coli, and other bacteria including Pseudomonas species, as well as non-bacterial pathogens [152-159]. The microbicidal effects of these molecules are exerted in nanomolar to low micromolar concentrations (1-5 $\mu \mathrm{g} / \mathrm{ml})$, and across physiological ranges of $\mathrm{pH}$ (5.5-8.0). PMPs and kinocidins appear to act synergistically with one another against microbial pathogens in vitro [152, 153]. Importantly, PMPs and kinocidins have also been shown to interact with one another to effect synergistic antimicrobial activity [152]. Thus, antimicrobial activities of PMPs and kinocidins observed in vitro and ex vivo are relevant to conditions which exist in vivo.

\section{Efficacy of PMPs and kinocidins ex vivo}

Multiple lines of evidence indicate that PMPs and kinocidins exert antimicrobial activities in relevant settings of infection ex vivo. The host defense roles of platelets of PMPs and kinocidins appear to be involved in limiting infection of vascular biomatrices. Mercier et al. [176] found that platelet activation by thrombin $30 \mathrm{~min}$ prior to bacterial inoculation correlated with a significant staphylocidal effect in an ex vivo model of infective endocarditis. Inhibition of $S$. aureus was greatest in simulated infective endocarditis vegetations during the post-colonization and proliferation phases of infection. Reinforcing this interpretation, synthetic mimetics of platelet kinocidins exert significantly greater antimicrobial efficacy in human blood and plasma ex vivo than in artificial medium, even after $2 \mathrm{~h}$ incubation in the biomatrices prior to inoculation of the target organisms [165]. Mercier et al. [177] also demonstrated that PMPs and kinocidins act in consort with conventional antibiotics to limit the evolution of simulated human infective endocarditis vegetations. In these studies, activated platelets alone, or in combination with antibiotics, inhibited the proliferation of $S$. aureus in model fluid or simulated vegetations over the initial 4 -h period ( $P<0.05$ vs controls). Nafcillin regimens were inhibitory beyond $4 \mathrm{~h}$ against ISP479C in both model phases. Interestingly, introduction of activated platelets inhibited glycopeptide-intermediate-susceptible S. aureus (GISA) proliferation in vegetations, but not in the chamber model fluid. The combination of platelets plus nafcillin or vancomycin significantly inhibited proliferation of the GISA strain in vegetations as compared to platelets or antibiotics alone. However, platelets were not significantly effective with or without nafcillin or vancomycin against a PMP-resistant strain of $S$. aureus.

Complementary data suggest that platelets protect against endovascular infections such as infective endocarditis by modulating the responses of adjacent platelets. For example, PMPs and kinocidins appear to modify S. aureus-induced platelet aggregation in vitro [100]. Exposure to sublethal concentrations of PMPs reduces the velocity and magnitude of platelet aggregation by S. aureus [99, 178, 179]. It is not yet known whether these peptides do so by modulating bacterium-to-platelet binding, or through other mechanisms. Filler et al. [180] have also demonstrated that platelets protect human umbilical vein endothelial cells (HUVECs) from in vitro injury due to $C$. albicans. In these studies, ${ }^{51}$ chromiumrelease from HUVECs due to $C$. albicans was reduced by $45 \%$ in the presence of a platelet-to-fungus ratio of 20:1. Moreover, HUVEC protection by platelets was associated with a $37 \%$ reduction in germ tube length in $C$. albicans after a 2-h exposure. Thus, it is conceivable that platelets defend vascular endothelium from bacterial injury or infection.

\section{Efficacy of PMPs and kinocidins in vivo}

Evidence from a body of recent literature demonstrates that platelets activate immediately and in high quantity in response to pathogens, as well as by soluble mediators and surface ligands expressed by infected host cells. As detailed herein and in previous comprehensive reviews [1, 6-10], platelets also contribute other key host defense effector functions, including: generation of microbicidal reactive oxygen species; facilitate complement fixation on microbes; internalization and clearance of pathogens from the bloodstream; generate and release of cytokines and 
chemokines that shape adaptive immune responses; execute antibody-dependent cell cytotoxicity against pathogens; and potentiation of antimicrobial mechanisms of leukocytes [181].

Previous investigations have established that PMPs and kinocidin levels in human plasma increase dramatically (four to sixfold) in settings of microbial infection in vivo. For example, the plasma levels of kinocidin PF4 increase in bacterial septicemia [182], streptococcal nephritis [183], and many other microbial infections. Similarly, Wilson et. al. [184] demonstrated that endotoxin prompts a marked increase in circulating levels of soluble CD62, an indicator of platelet $\alpha$-degranulation . Interestingly, unlike most other markers of inflammation, plasma concentrations of this biomarker progressively increased for up to $8 \mathrm{~h}$ after endotoxin injection in human volunteers. Therefore, PMPs and kinocidins are likely released immediately and over a window of time from platelets in response to relevant signals of inflammation and infection, as well as microorganisms themselves.

Consistent with these perspectives, platelet transfusion is now well established to have clear beneficial effects in a number of clinical situations, including infection and sepsis. It is known that sufficient platelet quantity and quality are important to homeostasis and host defense. For example, inherited platelet disorders including Wiscott-Aldrich Syndrome, May-Hegglin Anomaly, and Gray-Platelet Syndrome, strongly correlate with morbidity and mortality due to $S$. aureus and other infections [1, 4]. However, such conditions often represent a convergence of multiple disorders in cell-mediated immunity, making definition of platelet-specific roles in host defense difficult to interpret. Nonetheless, evidence for the role of platelets in immune defense against infection in humans comes from diseases of platelet dysfunction as highlighted below. Thus, the specific roles of platelets in host defense have been investigated in vivo using complementary approaches. The following discussion illustrates host defense roles of platelets in light of broader themes and recent examples of such clinical conditions.

\section{Deficiencies in platelet quantity}

It is now becoming clear from experimental as well as human studies that a threshold platelet count is an important determinant in the host defense repertoire against infection. Sullam et al. [185] used an experimental animal model to examine the role of platelets in defense against infective endocarditis. Viridans streptococci were used to induce endocarditis in animals with normal platelet counts, as compared with animals in which thrombocytopenia was conferred by platelet-specific antibody. Importantly, these study groups had no differences in leukocyte quantity or quality, or complement activity. Thrombocytopenic animals had significantly higher streptococcal densities in vegetation as compared with their counterparts with normal platelet counts. Other reports by Dankert et al. [146, 147, 186] likewise emphasize the concept that platelets act in host defense against infective endocarditis.

In humans, thrombocytopenia is now increasingly recognized as a significant, independent correlate of morbidity and mortality due to infection. For example, in oncological conditions and cancer chemotherapy, thrombocytopenia is an independent predictor of increased risk of morbidity and mortality due to bacterial or fungal infection [187-191]. Even in the absence of neutropenia, thrombocytopenia is positively correlated with incidence and severity of bacterial pneumonia in the elderly [188]. Similarly, Chang et al. [189] recently demonstrated thrombocytopenia to be an independent predictor of increased infection and related morbidity in liver transplant recipients. In this group, 50\% of patients with platelet counts of $\leq 30 \times 10^{9} / \mathrm{L}$ presented with infection within 30 days of transplantation, as compared with only $17 \%$ of patients with nadir platelet counts above this threshold. Likewise, Santolaya et al. [191] also evaluated five potential factors for risk of invasive bacterial infection: C-reactive protein serum level, hypotension, leukemia relapse, thrombocytopenia $\left(\leq 50 \times 10^{9} / \mathrm{L}\right)$, or chemotherapy. Thrombocytopenia was found to be an independent risk factor for bacterial infection in $12 \%$ of children in this cohort study (sensitivity, specificity, positive and negative predictive values of $92,76,82$, and $90 \%$, respectively). In a similar investigation, Yoshida et al. [192] employed multivariate analysis to find that reduced platelet count is an independent predictor of severe bacteremia in healthcare settings. Substantiating these data, Mavrommatis et al. [193] distinguished platelet function from overall coagulation responses to infection in humans. In the initial state, uncomplicated sepsis correlates with increases in blood levels of fibrinopeptide-A, a PMP, and the kinocidin PF4. Increased levels of such molecules were temporally associated with a reduction in platelet count, indicating clearance of activated upon degranulation. However, platelet responsivity is often reduced as coagulation factors are depleted in sepsis, as in other severe infections.

\section{Deficiencies in platelet activation}

The above studies strongly suggest that a threshold platelet count is an important barrier to infection. Beyond their number, the ability of platelets to sense and respond to soluble or cellular signals of infection appears to play a significant role in host defense. While platelets can sense and respond to pathogens, key activators of platelets are host signals emanating from injured or infected tissues. For 
example, tissue infection often results in the elaboration of tissue factor, which in turn activates the cleavage of thrombin from pro-thrombin. In a recent investigation, Sun et al. [194] reported that deficiencies in thrombin generation increase host susceptibility to group A streptococcal infection. In these studies, mice made deficient in factor $\mathrm{V}$ (FV) either as circulating in plasma or contained in platelet compartments, were challenged with group A streptococcal infection. A reduction of FV in either pool was associated with marked increases in infection-caused mortality, in comparison to mice with normal levels of FV. Moreover, fibrinogen deficiency also yielded a significant increase in mortality to infection relative to controls. These findings support the concept that constituents mediating platelet signaling and response in local platelet activation and thrombosis contribute to host defense against bacterial pathogenesis.

\section{Future perspectives}

Immune system cells have evolved highly sophisticated molecular and cellular systems with which to detect and defend against infection. Platelets represent a highly specialized member of this repertoire. Although these cells have no nucleus, they retain unambiguous structural and functional attributes of host defense effector cells. Platelets are now known to express TLRs and many other typical characteristics of innate immune effector cells that play key and multifaceted roles in host defense against infection. Evidence substantiating this role derives from an integration of findings over the last decade, including: (1) the discovery of PMPs and kinocidins released from platelets; (2) experimental animal models in which platelets significantly contribute to host defense; and (3) increased susceptibility to infection in clinical deficiencies of platelet quantity or quality. Thus, platelets are sentinel cells that can detect infection and deliver antimicrobial effector molecules in innate defense and which potentiate the efficacy of leukocytes and other host defense systems. In turn, bacterial pathogens have evolved myriad surface proteins and other mechanisms by which to interact with platelets. In some pathogens, adherence and activation of platelets appear to subvert platelet responses and contribute to virulence. These advances emphasize the importance of future studies of human diseases and animal models to elucidate the roles of platelets in prevention or limitation of infection. Moreover, studies of specific platelet inhibitors may reveal important insights into platelet function in human infections, and lead to new anti-infective agents or strategies. For example, novel anti-infectives designed upon PMPs and kinocidins have already demonstrated efficacy against antibiotic-resistant pathogens in vivo. In addition, such molecules or immunobiotics appear to amplify the efficacy of conventional antimicrobial agents, and therefore might be useful to restore or enhance or efficacies of conventional antiinfective against resistant pathogens.

Acknowledgments This paper summarizes a body of information that derives from a significant effort on the part of numerous investigators over many years of work. Although not every report could be cited in the space of this review, genuine appreciation is extended to all of the talented individuals working in this area. M.R.Y was supported in-part by grants AI39001 and AI48031 from the National Institutes of Health.

Open Access This article is distributed under the terms of the Creative Commons Attribution Noncommercial License which permits any noncommercial use, distribution, and reproduction in any medium, provided the original author(s) and source are credited.

\section{References}

1. Yeaman MR, Bayer AS (2006) Platelets in antimicrobial host defense. In: Michelson A (ed) Platelets, 2nd edn. Academic, New York, pp 727-755

2. Nachum R, Watson SW, Sullivan JD Jr, Siegel SE (1980) Antimicrobial defense mechanisms in the horseshoe crab, Limulus polyphemus: preliminary observations with heat-derived extracts of Limulus amoebocyte lysate. J Invertebr Pathol 32:51-58

3. Maluf NSR (1939) The blood of arthropods. Q Rev Biol 14:149-191

4. Weksler BB (1992) Platelets. In: Gallin JI, Goldstein IM, Snyderman R (eds) Inflammation: basic principles and clinical correlates, 2nd edn. Raven, New York, pp 543-557

5. Tocantins LM (1938) The mammalian blood platelet in health and disease. Medicine 17:155-257

6. Klinger MH, Jelkmann W (2002) Role of blood platelets in infection and inflammation. J Interferon Cytokine Res 22:913-922

7. Yeaman MR (1997) The role of platelets in antimicrobial host defense. Clin Infect Dis 25:951-968

8. Yeaman MR, Bayer AS (1999) Antimicrobial peptides from platelets. Drug Resist Updat 2:116-126

9. Elzey BD, Sprague DL, Ratliff TL (2005) The emerging role of platelets in adaptive immunity. Cell Immunol 238:1-9

10. Fitzgerald JR, Foster TJ, Cox D (2006) The interaction of bacterial pathogens with platelets. Nat Rev Microbiol 4:445-457

11. Ford I, Douglas CW (1997) The role of platelets in infective endocarditis. Platelets 8:285-294

12. White JG (1972) Platelet morphology and function. In: Williams WJ, Beutler E, Erslev AJ, Rundles RW (eds) Hematology. McGraw-Hill, New York, pp 1023-1039

13. Marcus AJ (1969) Platelet function. N Eng J Med 280: 1213, 1278,1330

14. Heyssel RM (1961) Determination of human platelet survival utilizing ${ }^{14} \mathrm{C}$-labelled serotonin. J Clin Invest 40:2134-2138

15. Murphy EA, Robinson GA, Rowsell A (1967) The pattern of platelet disappearance. Blood 30:26-31

16. Harker LA, Finch CA (1969) Thrombokinetics in man. J Clin Invest 48:963-1969

17. Colman RW (1991) Receptors that activate platelets. Proc Soc Exp Biol Med 197:242-248 
18. MacFarlane DE, Mills DCB (1975) The effects of ATP on platelets: evidence against the central role of released ADP in primary aggregation. Blood 46:309-314

19. MacFarlane DE, Walsh PN, Mills DCB, Holmsen H, Day HJ (1975) The role of thrombin in ADP-induced platelet aggregation and release: a critical evaluation. $\mathrm{Br} \mathrm{J}$ Haematol 30:457-464

20. Davies TA, Fine RE, Johnson RJ, Levesque CA, Rathbun WH, Seetoo KF, Smith SJ, Strohmeier G, Volicer L, Delva L, Simons ER (1993) Non-age related differences in thrombin responses by platelets from male patients with advanced Alzheimer's disease. Biochem Biophys Res Commun 194:537-543

21. Rosenfeld SI, Looney RJ, Leddy JP (1985) Human platelet Fc receptor of immunoglobulin G. J Clin Invest 76:2317-2322

22. Joseph M, Auriault C (1983) A new function for platelets: IgE-dependent killing of schistosomes. Nature 303:810-812

23. Bout D, Joseph M, Ponet M (1986) Rat resistance to schistosomiasis: platelet-mediated cytotoxicity induced by C-reactive protein. Science 231:153-156

24. Ochenhouse CF, Magowan C, Chulay JD (1989) Activation of monocytes and platelets by monoclonal antibodies or malariainfected erythrocytes binding to CD36 surface receptor in vitro. J Clin Invest 84:468-475

25. Cosgrove LJ, de Apice AJ, Haddad A, Pedersen J, McKenzie IF (1987) CR3 receptors on platelets and it role in the prostaglandin metabolic pathway. Immunol Cell Biol 65:453-460

26. Pancré V, Monte D, Delanoye A, Capron A, Auriault C (1990) Interleukin-6, the main mediator of interaction between monocytes and platelets in killing of Schistosoma mansoni. Eur Cytokine Netw 1:15-19

27. Peng J, Friese P, George JN, Dale GL, Burstein SA (1994) Alteration of platelet function in dogs mediated by interleukin-6. Blood 83:398-403

28. Clemetson KJ, Clemetson JM, Proudfoot AE, Power CA, Baggiolini M, Wells TN (2000) Functional expression of CCR1, CCR3, CCR4, and CXCR4 chemokine receptors on human platelets. Blood 96:4046-4054

29. Bureau MF, DeClerck F, Lefort J, Arreto CD, Vargaftig BB (1992) Thromboxane $A_{2}$ accounts for bronchoconstriction, but not for platelet sequestration and microvascular albumin exchanges induced by f-met-leu-phe in the guinea pig lung. J Pharmacol Exp Ther 260:8832-8840

30. Coyle AJ, Vargaftig BB (1995) Animal models for investigating the allergic and inflammatory properties of platelets. In: Joseph M (ed) Immunopharmacology of platelets. Academic, London, pp 21-30

31. Czapiga M, Gao JL, Kirk A, Lekstrom-Himes J (2005) Human platelets exhibit chemotaxis using functional $\mathrm{N}$-formyl peptide receptors. Exp Hematol 33:73-84

32. Jaff MS, McKenna D, McCann SR (1985) Platelet phagocytosis: a probable mechanism of thrombocytopenia in Plasmodium falciparum infection. J Clin Pathol 38:1318-1319

33. Movat HZ, Weiser WJ, Glynn MF, Mustard JF (1965) Platelet phagocytosis and aggregation. J Cell Biol 27:531-543

34. Cognasse F, Hamzeh H, Chavarin P, Acquart S, Genin C, Garraud O (2005) Evidence of Toll-like receptor molecules on human platelets. Immunol Cell Biol 83:196-198

35. Shiraki R, Inoue N, Kawasaki S, Takei A, Kadotani M, Ohnishi Y, Ejiri J, Kobayashi S, Hirata K, Kawashima S, Yokoyama M (2004) Expression of Toll-like receptors on human platelets. Thromb Res 113:379-385

36. Aslam R, Speck ER, Kim M, Crow AR, Bang KW, Nestel FP, Ni H, Lazarus AH, Freedman J, Semple JW (2006) Platelet Tolllike receptor expression modulates lipopolysaccharide-induced thrombocytopenia and tumor necrosis factor-alpha production in vivo. Blood 107:637-641
37. Cognasse F, Hamzeh-Cognasse H, Lafarge S, Delezay O, Pozzetto B, McNicol A, Garraud O (2008) Toll-like receptor 4 ligand can differentially modulate the release of cytokines by human platelets. Br J Haematol 141:84-91

38. Blair P, Rex S, Vitseva O, Beaulieu L, Tanriverdi K, Chakrabarti S, Hayashi C, Genco CA, Iafrati M, Freedman JE (2009) Stimulation of Toll-like receptor 2 in human platelets induces a thromboinflammatory response through activation of phosphoinositide 3-kinase. Circ Res 104:346-354

39. Zhang G, Han J, Welch EJ, Ye RD, Voyno-Yasenetskaya TA, Malik AB, Du X, Li Z (2009) Lipopolysaccharide stimulates platelet secretion and potentiates platelet aggregation via TLR4/ MyD88 and the cGMP-dependent protein kinase pathway. J Immunol 182:7997-8004

40. Clark SR, Ma AC, Tavener SA, McDonald B, Goodarzi Z, Kelly MM, Patel KD, Chakrabarti S, McAvoy E, Sinclair GD, Keys EM, Allen-Vercoe E, Devinney R, Doig CJ, Green FH, Kubes P (2007) Platelet TLR4 activates neutrophil extracellular traps to ensnare bacteria in septic blood. Nat Med 13:463-469

41. Scott T, Owens MD (2008) Thrombocytes respond to lipopolysaccharide through Toll-like receptor-4, and MAP kinase and NF-kappaB pathways leading to expression of interleukin-6 and cyclooxygenase-2 with production of prostaglandin E2. Mol Immunol 45:1001-1008

42. Miedzobrodzki J, Panz T, Płonka PM, Zajac K, Dracz J, Pytel K, Mateuszuk Ł, Chłopicki S (2008) Platelets augment respiratory burst in neutrophils activated by selected species of gram-positive or gram-negative bacteria. Folia Histochem Cytobiol 46:383-388

43. Blumberg N, Spinelli SL, Francis CW, Taubman MB, Phipps RP (2009) The platelet as an immune cell-CD40 ligand and transfusion immunomodulation. Immunol Res. 2009 [Epub ahead of print]

44. Bancsi MJLF, Thompson J, Bertina RM (1994) Stimulation of monocyte tissue factor expression in an in vitro model of bacterial endocarditis. Infect Immun 62:5669-5672

45. Drake TA, Pang M (1988) Staphylococcus aureus induces tissue factor expression in cultured human cardiac valve endothelium. J Infect Dis 157:749-756

46. Drake TA, Rodgers GM, Sande MA (1984) Tissue factor is a major stimulus for vegetation formation in enterococcal endocarditis in rabbits. J Clin Invest 73:1750-1753

47. White JG (1987) Views of the platelet at rest and at work. Ann NY Acad Sci 509:156-176

48. White JG, Sauk JJ (1984) Microtubule coils in spread blood platelets. Blood 64:470-478

49. Price B, Flaumenhaft R (2009) Platelet $\alpha$-granules: basic biology and clinical correlates. Blood Rev 23:177-189

50. Scheld WM, Valone JA, Sande MA (1978) Bacterial adherence in the pathogenesis of infective endocarditis: interaction of dextran, platelets, \& fibrin. J Clin Invest 61:1394-1404

51. Durack DT (1975) Experimental bacterial endocarditis. IV. Structure and evolution of very early lesions. J Clin Pathol 45:81-89

52. Calderone RA, Rotondo MF, Sande MA (1978) Candida albicans endocarditis: ultrastructural studies of vegetation formation. Infect Immun 20:279-289

53. Durack DT, Beeson PB, Petersdorf RG (1973) Experimental bacterial endocarditis. III. Production of progress of the disease in rabbits. Br J Exp Pathol 54:142-151

54. Sullam PM, Drake TA, Sande MA (1985) Pathogenesis of endocarditis. Am J Med 78(Suppl 6B):110-115

55. Ferguson DJP, McColm AA, Savage TJ, Ryan DM, Acred P (1986) A morphological study of experimental rabbit staphylococcal endocarditis and aortitis. I. Formation and effect of infected and uninfected vegetations on the aorta. Br J Exp Pathol 67:667-678 
56. Scheld WM, Sande MA (1995) Endocarditis and intravascular infections. In: Mandell GL, Bennet JE, Dolin R (eds) Principles and practice of infectious diseases, 5th edn. Churchill Livingstone, New York, pp 740-782

57. Clawson CC (1977) Role of platelets in the pathogenesis of endocarditis. In: Infectious endocarditis. Am Heart Assoc Monogr 52:24-27

58. Roberts WC, Buchbinder NA (1972) Right-sided valvular infective endocarditis: a clinicopathologic study of 12 necropsy patients. Am J Med 53:7-19

59. Buchbinder NA, Roberts WC (1972) Left-sided valvular infective endocarditis: a study of 45 necropsy patients. Am J Med 53:20-35

60. Vinter DW, Burkel WE, Wakefield TW, Graham LM, Whitehouse WM Jr, Stanley JC, Ford JW (1984) Radioisotope-labeled platelet studies and infection of vascular grafts. J Vasc Surg 6:921-923

61. Osler W (1886) On certain problems in the physiology of the blood corpuscles. Med News 48:365-370, 393-399, 421-425

62. Cheung AL, Fischetti VA (1990) The role of fibrinogen in staphylococcal adherence to catheters in vitro. J Infect Dis 161:1177-1186

63. Piguet PF, Vesin C, Ryser JE, Senaldi G, Grau GF, TachiniCottier F (1993) An effector role for platelets in systemic and local lipopolysaccharide-induced toxicity in mice, mediated by a CD11a- and CD54a-dependent interaction with endothelium. Infect Immun 61:82-87

64. Smith CW (1993) Leukocyte-endothelial cell interaction. Semin Hematol 30:45-55

65. Maisch PA, Calderone RA (1980) Adherence of Candida albicans to a fibrin-platelet matrix formed in vitro. Infect Immun 27:650-656

66. Klotz SA, Harrison JL, Misra RP (1989) Aggregated platelets enhance adherence of Candida yeasts to endothelium. J Infect Dis 160:669-677

67. Yeaman MR, Norman DC, Bayer AS (1992) Staphylococcus aureus susceptibility to thrombin-induced platelet microbicidal protein is independent of platelet adherence or aggregation in vitro. Infect Immun 60:2368-2374

68. Sullam PM, Valone FH, Mills J (1987) Mechanisms of platelet aggregation by viridans group streptococci. Infect Immun 55:1743-1750

69. Robert R, Senet JM, Mahaza C, Annaix V, Miegeville M, Bouchara JP, Tronchin G, Marot-Leblond A (1992) Molecular basis of the interaction between Candida albicans, fibrinogen, and platelets. J Mycol Med 2:19-25

70. Herzberg MC, Brintzenhofe KL, Clawson CC (1983) Aggregation of human platelets and adhesion of Streptococcus sanguis. Infect Immun 39:1457-1469

71. Herzberg MC, Gong K, MacFarlane GD, Erickson PR, Soberay AH, Krebsbach PH, Gopalraj M, Schilling K, Bowen WH (1990) Phenotypic characterization of Streptococcus sanguis virulence factors associated with bacterial endocarditis. Infect Immun 58:515-522

72. Nicolau DP, Freeman CD, Nightingale CH, Quintiliani R, Coe CJ, Maderazo EG, Cooper BW (1993) Reduction of bacterial titers by low-dose aspirin in experimental aortic valve endocarditis. Infect Immun 61:1593-1595

73. Clawson CC, White JG (1971) Platelet interaction with bacteria. II. Fate of bacteria. Am J Pathol 65:381-398

74. Clawson CC, White JG (1971) Platelet interaction with bacteria. I. Reaction phases and effects of inhibitors. Am J Pathol 65:367-380

75. Clawson CC (1973) Platelet interaction with bacteria. III. Ultrastructure. Am J Pathol 70:449-472

76. Clawson CC, Rao GHR, White JG (1975) Platelet interaction with bacteria. IV. Stimulation of the release reaction. Am J Pathol 81:411-420
77. Forrester LJ, Campbell BJ, Berg JN, Barrett JT (1985) Aggregation of platelets by Fusobacterium necrophorum. J Clin Microbiol 22:245-249

78. Czuprynski CJ, Balish E (1981) Interaction of rat platelets with Listeria monocytogenes. Infect Immun 33:103-108

79. Copley AL, Maupin B, Balea T (1959) The agglutinant and adhesive behaviour of isolated human and rabbit platelets in contact with various strains of mycobacteria. Acta Tuberc Scand 37:151-161

80. Kessler CM, Nussbaum E, Tuazon CU (1987) In vitro correlation of platelet aggregation with occurrence of disseminated intravascular coagulation and subacute bacterial endocarditis. J Lab Clin Med 109:647-652

81. Timmons S, Huzoor-Akbar A, Grabarek J, Kloczewiak M, Hawiger J (1986) Mechanism of human platelet activation by endotoxic glycolipid-bearing mutant Re595 of Salmonella minnesota. Blood 68:1015-1023

82. Mandell GL, Hook EW (1969) The interaction of platelets, Salmonella, and mouse peritoneal macrophages. Proc Soc Exp Biol Med 132:757-759

83. Simmonet M, Triadou P, Frehel C, Morel-Kopp M-C, Kaplan C, Berche P (1992) Human platelet aggregation by Yersinia pseudotuberculosis is mediated by invasin. Infect Immun 60:366-373

84. Sigurdsson AF, Gudmundsson S (1989) The etiology of bacterial cellulitis as determined by fine-needle aspiration. Scand $\mathbf{J}$ Infect Dis 21:537-542

85. Diekema DJ, Pfaller MA, Schmitz FJ, Smayevsky J, Bell J, Jones RN, Beach M (2001) Survey of infections due to Staphylococcus species: frequency of occurrence and antimicrobial susceptibility of isolates collected in the United States, Canada, Latin America, Europe, and the Western Pacific region for the SENTRY Antimicrobial Surveillance Program, 1997-1999. Clin Infect Dis 32:S114-S132

86. Carratala J, Roson B, Fernandez-Sabe N, Shaw E, del Rio O, Rivera A, Gudiol F (2003) Factors associated with complications and mortality in adult patients hospitalized for infectious cellulitis. Eur $\mathrm{J}$ Clin Microbiol Infect Dis 22:151-157

87. Brook I, Frazier EH (1995) Clinical features and aerobic and anaerobic microbiological characteristics of cellulitis. Arch Surg 130:786-792

88. Hoen B, Alla F, Selton-Suty C, Beguinot I, Bouvet A, Briancon S, Casalta JP, Danchin N, Delahaye F, Etienne J, Le Moing V, Leport C, Mainardi JL, Ruimy R, Vandenesch F (2002) Changing profile of infective endocarditis: results of a 1-year survey in France. JAMA 288:75-81

89. Fowler VG Jr, Miro JM, Hoen B, Cabell CH, Abrutyn E, Rubinstein E, Corey GR, Spelman D, Bradley SF, Barsic B, Pappas PA, Anstrom KJ, Wray D, Fortes CQ, Anguera I, Athan E, Jones P, van der Meer JT, Elliott TS, Levine DP, Bayer AS (2005) Staphylococcus aureus endocarditis: a consequence of medical progress. JAMA 293:3012-3021

90. Miro JM, Anguera I, Cabell CH, Chen AY, Stafford JA, Corey GR, Olaison L, Eykyn S, Hoen B, Abrutyn E, Raoult D, Bayer A, Fowler VG Jr (2005) Staphylococcus aureus native valve infective endocarditis: report of 566 episodes from the International Collaboration on Endocarditis Merged Database. Clin Infect Dis 41:507-514

91. Wisplinghoff H, Seifert H, Wenzel RP, Edmond MB (2003) Current trends in the epidemiology of nosocomial bloodstream infections in patients with hematological malignancies and solid neoplasms in hospitals in the United States. Clin Infect Dis 36:1103-1110

92. Wisplinghoff H, Bischoff T, Tallent SM, Seifert H, Wenzel RP, Edmond MB (2004) Nosocomial bloodstream infections in US 
hospitals: analysis of 24, 179 cases from a prospective nationwide surveillance study. Clin Infect Dis 39:309-317

93. Wisplinghoff $\mathrm{H}$, Seifert $\mathrm{H}$, Tallent SM, Bischoff T, Wenzel RP, Edmond MB (2003) Nosocomial bloodstream infections in pediatric patients in United States hospitals: epidemiology, clinical features and susceptibilities. Pediatr Infect Dis J 22:686-691

94. Mylotte JM, Kahler L, McCann C (2001) Community-acquired bacteremia at a teaching versus a nonteaching hospital: impact of acute severity of illness on 30-day mortality. Am J Infect Control 29:13-19

95. Moreillon P, Que Y-A, Glauser MP (2005) Staphylococcus aureus (including staphylococcal toxic shock). In: Mandell GL, Bennett JE, Dolin R (eds) Principles and practice of infectious diseases, 6th edn. Elsevier, Philadelphia, pp 2321-2351

96. Bayer AS, Ramos MD, Menzies BE, Yeaman MR, Shen AJ, Cheung AL (1997) Hyperproduction of alpha-toxin by Staphylococcus aureus results in paradoxically reduced virulence in experimental endocarditis: a host defense role for platelet microbicidal proteins. Infect Immun 65:4652-4660

97. Hawiger J, Streackley S, Hammond D, Chang C, Timmons S, Glick A, desPrez RM (1979) Staphylococcal-induced human platelet injury mediated by protein A and immunoglobulin G Fc receptor. J Clin Invest 64:931-937

98. Sullam PM, Payan DG, Dazin PF, Valone FH (1990) Binding of viridans group streptococci to human platelets: a quantitative analysis. Infect Immun 58:3802-3806

99. Yeaman MR, Sullam PM, Dazin PF, Bayer AS (1992) Characterization of Staphylococcus aureus-platelet binding by quantitative flow cytometric analysis. J Infect Dis 166:65-73

100. Bayer AS, Sullam PM, Ramos M, Li C, Cheung AL, Yeaman MR (1995) Staphylococcus aureus induces platelet aggregation via a fibrinogen-dependent mechanism which is independent of principal platelet glycoprotein IIb/IIIa fibrinogen binding domains. Infect Immun 63:3634-3641

101. Siboo IR, Chambers HF, Sullam PM (2005) Role of SraP, a serine-rich surface protein of Staphylococcus aureus in binding to human platelets. Infect Immun 73:2273-2280

102. Niemann S, Spehr N, van Aken H, Morgenstern E, Peters G, Herrmann M, Kehrel BE (2004) Soluble fibrin is the main mediator of Staphylococcus aureus adhesion to platelets. Circulation 110:193-200

103. Cheung AL, Krishnan M, Jaffe EA, Fischetti VA (1991) Fibrinogen acts as a bridging molecule in the adherence of Staphylococcus aureus to cultured human endothelial cells. J Clin Invest 87:2236-2245

104. Clawson CC, White JG, Herzberg MC (1980) Platelet interaction with bacteria. VI. Contrasting the role of fibrinogen and fibronectin. Am J Hematol 9:43-53

105. Toy PTCY, Lai L-W, Drake TA, Sande MA (1985) Effect of fibronectin on adherence of Staphylococcus aureus to fibrin thrombi in vitro. Infect Immun 48:83-86

106. Herrmann M, Suchard SJ, Boxer LA, Waldvogel FA, Lew PD (1991) Thrombospondin binds to Staphylococcus aureus and promotes staphylococcal adherence to surfaces. Infect Immun 59:271-288

107. Loughman A, Fitzgerald JR, Brennan MP, Higgins J, Downer R, Cox D, Foster TJ (2005) Roles for fibrinogen, immunoglobulin and complement in platelet activation promoted by Staphylococcus aureus clumping factor A. Mol Microbiol 57:804-818

108. Nguyen T, Ghebrehiwet B, Peerschke EI (2000) Staphylococcus aureus protein A recognizes platelet $\mathrm{gClqR} / \mathrm{p} 33$ : a novel mechanism for staphylococcal interactions with platelets. Infect Immun 68:2061-2068

109. Youssefian T, Drouin A, Masse JM, Guichard J, Cramer EM (2002) Host defense role of platelets: engulfment of HIV and
Staphylococcus aureus occurs in a specific subcellular compartment and is enhanced by platelet activation. Blood 99:4021-4029

110. Brennan M, Loughman A, Devocelle M, Arasu S, Chubb AJ, Foster TJ, Cox D (2009) Elucidating the role of Staphylococcus epidermidis serine-aspartate repeat protein $\mathrm{G}(\mathrm{SdrG})$ in platelet activation. J Thromb Haemost 7:1364-1372

111. Gong K, Herzberg MC (1997) Streptococcus sanguis expresses a 150-kilodalton two-domain adhesin: characterization of several independent adhesin epitopes. Infect Immun 65:3815-3821

112. Zimmerman TS, Spregelberg HL (1975) Pneumococcus-induced serotonin release from human platelets. Identification of the participating plasma/serum factor as immunoglobulin. J Clin Invest 56:828-834

113. Ford I, Douglas CWI, Preston SE, Lawless A, Hampton KK (1993) Mechanisms of platelet aggregation by Streptococcus sanguis, a causative organism in infective endocarditis. $\mathrm{Br}$ J Hematol 84:85-100

114. Kurpiewski GE, Forrester LJ, Campbell BJ, Barrett JT (1983) Platelet aggregation by Streptococcus pyogenes. Infect Immun 39:704-708

115. Johnson CM, Bowie EJW (1992) Pigs with von Willebrand disease may be resistant to experimental infective endocarditis. J Lab Clin Med 120:553-558

116. Kerrigan SW, Jakubovics NS, Keane C, Maguire P, Wynne K, Jenkinson HF, Cox D (2007) Role of Streptococcus gordonii surface proteins SspA/SspB and Hsa in platelet function. Infect Immun 75:5740-5747

117. Sullam PM, Jarvis GA, Valone FH (1988) Role of immunoglobulin $G$ in platelet aggregation by viridans group streptococci. Infect Immun 56:2907-2911

118. Bensing BA, Rubens CE, Sullam PM (2001) Genetic loci of Streptoccus mitis that mediate binding to human platelets. Infect Immun 69:1373-1380

119. Mitchell J, Siboo IR, Takamatsu D, Chambers HF, Sullam PM (2007) Mechanism of cell surface expression of the Streptococcus mitis platelet binding proteins $\mathrm{PblA}$ and $\mathrm{PblB}$. Mol Microbiol 64:844-857

120. Mitchell J, Sullam PM (2009) Streptococcus mitis phage-encoded adhesins mediate attachment to $\alpha-2-8$-linked sialic acid residues on platelet membrane gangliosides. Infect Immun 77:3485-3490

121. Xiong YQ, Bensing BA, Bayer AS, Chambers HF, Sullam PM (2008) Role of the serine-rich surface glycoprotein GspB of Streptococcus gordonii in the pathogenesis of infective endocarditis. Microb Pathog 45:297-301

122. Takamatsu D, Bensing BA, Sullam PM (2004) Four proteins encoded in the gspB-secY2A2 operon of Streptococcus gordonii mediate the intracellular glycosylation of the platelet-binding protein GspB. J Bacteriol 186:7100-7111

123. Ohba M, Shibazaki M, Sasano T, Inoue M, Takada H, Endo Y (2004) Platelet responses and anaphylaxis-like shock induced in mice by intravenous injection of whole cells of oral streptococci. Oral Microbiol Immunol 19:26-30

124. Rasmussen M, Eden A, Bjorck L (2000) SclA, a novel collagenlike surface protein of Streptococcus pyogenes. Infect Immun 69:6370-6377

125. Pietrocola G, Schubert A, Visai L, Torti M, Fitzgerald JR, Foster TJ, Reinscheid DJ, Speziale P (2005) FbsA, a fibrinogen-binding protein from Streptococcus agalactiae, mediates platelet aggregation. Blood 105:1052-1059

126. Coutinho IR, Berk RS, Mammen E (1988) Platelet aggregation by a phospholipase C from Pseudomonas aeruginosa. Thromb Res 51:495-505

127. Machado GB, de Assis MC, Leão R, Saliba AM, Silva MC, Suassuna JH, de Oliveira AV, Plotkowski MC (2009) ExoU- 
induced vascular hyperpermeability and platelet activation in the course of experimental Pseudomonas aeruginosa pneumosepsis. Shock [Epub ahead of print]

128. Shepel M, Boyd J, Luider J, Gibb AP (2001) Interaction of Yersinia enterocolitica and Y. pseudotuberculosis with platelets. J Med Microbiol 50:1030-1038

129. Bhat MA, Bhat JI, Kawoosa MS, Ahmad SM, Ali SW (2009) Organism-specific platelet response and factors affecting survival in thrombocytopenic very low birth weight babies with sepsis. J Perinatol 29:702-708

130. Fodor J (1887) Die fahigkeit des blutes bakterien zu vernichten. Dtsch Med Wochenschr 13:745-747

131. Gengou O (1901) De l'origine de l'axenine de serums normaux. Ann Inst Pasteur (Paris) 15:232-245

132. Hirsch JG (1960) Comparative bactericidal activities of blood serum and plasma serum. J Exp Med 112:15-22

133. Jago R, Jacox RF (1961) Cellular source and character of a heatstable bactericidal property associated with rabbit and rat platelets. J Exp Med 113:701-709

134. Weksler BB (1971) Induction of bactericidal activity in human platelets. Clin Res 19:434-435

135. Kahn RA, Flinton LJ (1974) The relationship between platelets and bacteria. Blood 44:715-721

136. Miragliotta G, Lafata M, Jirilla E (1988) Antibacterial activity mediated by human platelets. Agents Actions 25:401-406

137. Carroll SF, Martinez RJ (1981) Antibacterial peptide from normal rabbit serum. I. Isolation from whole serum, activity, and microbiologic spectrum. Biochemistry 20:5973-5981

138. Carroll SF, Martinez RJ (1981) Antibacterial peptide from normal rabbit serum. II. Compositional microanalysis. Biochemistry 20:5981-5987

139. Carroll SF, Martinez RJ (1981) Antibacterial peptide from normal rabbit serum. III. Inhibition of microbial electron transport. Biochemistry 20:5988-5994

140. Myrvik QN (1956) Serum bactericidins active against Grampositive bacteria. Ann NY Acad Sci 66:391-400

141. Myrvik QN, Leake ES (1960) Studies on antibacterial factors in mammalian tissues and fluids. IV. Demonstration of two nondialyzable components in the serum bactericidin system for Bacillus subtilis. J Immunol 84:247-250

142. Johnson FB, Donaldson DM (1968) Purification of staphylocidal $\beta$-lysin from rabbit serum. J Bacteriol 96:589-595

143. Donaldson DM, Tew JG (1977) $\beta$-lysin of platelet origin. Bacteriol Rev 41:501-512

144. Weksler BB, Nachman RL (1971) Rabbit platelet bactericidal protein. J Exp Med 134:1114-1130

145. Tew JG, Roberts RR, Donaldson DM (1974) Release of $\beta$-lysin from platelets by thrombin and by a factor produced in heparinized blood. Infect Immun 9:179-186

146. Dankert J (1988) Role of platelets in early pathogenesis of viridans group streptococcal endocarditis. PhD dissertation, University of Groningen, The Netherlands

147. Dankert J, van der Werff J, Zaat SAJ, Joldersma W, Klein D, Hess J (1995) Involvement of bactericidal factors from thrombin-stimulated platelets in clearance of adherent viridans streptococci in experimental infective endocarditis. Infect Immun 63:663-671

148. Darveau RP, Blake J, Seachord CL, Cosand WL, Cunningham MD, Cassiano-Cough L, Maloney G (1992) Peptide related to the carboxy-terminus of human platelet factor IV with antibacterial activity. J Clin Invest 90:447-455

149. Dürr M, Peschel A (2002) Chemokines meet defensins: the merging concepts of chemoattractants and antimicrobial peptides in host defense. Infect Immun 70:6515-6517

150. Cole AM, Ganz T, Liese AM, Burdick MD, Liu L, Strieter RM (2001) Cutting edge: IFN-inducible ELR- CXC chemokines display defensin-like antimicrobial activity. J Immunol 167:623-627

151. Yang D, Chen Q, Hoover DM, Staley P, Tucker KD, Lubkowski J, Oppenheim JJ (2003) Many chemokines including CCL20/MIP-3 $\alpha$ display antimicrobial activity. J Leukoc Biol $74: 448-455$

152. Tang YQ, Yeaman MR, Selsted ME (1995) Microbicidal and synergistic activities of human platelet factor-4 (hPF-4) and connective tissue activating peptide-3 (CTAP-3). Blood 86:556a

153. Tang YQ, Yeaman MR, Selsted ME (2002) Antimicrobial proteins from human platelets. Infect Immun 70:6524-6533

154. Yeaman MR, Puentes SM, Norman DC, Bayer AS (1992) Partial purification and staphylocidal activity of thrombin-induced platelet microbicidal protein. Infect Immun 60:1202-1209

155. Yeaman MR, Tang Y-Q, Shen AJ, Bayer AS, Selsted ME (1997) Purification and in vitro activities of rabbit platelet microbicidal proteins. Infect Immun 65:1023-1031

156. Yount NY, Gank KD, Xiong YQ, Bayer AS, Pender T, Welch WH, Yeaman MR (2004) Platelet microbicidal protein-1: structural themes of a multifunctional antimicrobial peptide. Antimicrob Agents Chemother 48:4395-4404

157. Yeaman MR, Yount NY (2005) Code among chaos: immunorelativity and the AEGIS model of antimicrobial peptides. Microbe 71:21-27

158. Yeaman MR (2004) Antimicrobial peptides from platelets in defense against cardiovascular infections. In: Devine DA, Hancock REW (eds) Mammalian host defense peptides. Cambridge University Press, Cambridge, pp 279-322

159. Yeaman MR, Waring AJ, Yount NY, Gank KD, Wiese R, Bayer AS, Welch WH (2007) Modular determinants of antimicrobial activity in platelet factor-4 family kinocidins. Biochem Biophys Acta 1768:609-619

160. Yount NY, Andrés MT, Fierro JF, Yeaman MR (2007) The $\gamma$-core motif correlates with antimicrobial activity in Cys-containing kaliocin-1 originating from transferrins. Biochem Biophys Acta 1768:2862-2872

161. Yeaman MR, Yount NY (2007) Unifying themes in host defense effector polypeptides. Nature Rev Microbiol 5:727-740

162. Yount NY, Waring AJ, Gank KD, Welch WH, Kupferwasser D, Yeaman MR (2007) Structural correlates of antimicrobial activity in IL-8 and related human kinocidins. Biochem Biophys Acta 1768:598-608

163. Yount NY, Yeaman MR (2004) Multidimensional signatures in antimicrobial peptides. Proc Natl Acad Sci USA 101:7363-7368

164. Anderson RC, Rehders M, Yu PL (2008) Antimicrobial fragments of the pro-region of cathelicidins and other immune peptides. Biotechnol Lett 30:813-818

165. Yeaman MR, Gank KD, Bayer AS, Brass EP (2002) Synthetic peptides that exert antimicrobial activities in whole blood and blood-derived matrices. Antimicrob Agents Chemother 46:3883-3891

166. Azizi N, Li C, Shen AJ, Bayer AS, Yeaman MR (1996) Staphylococcus aureus elicits release of platelet microbicidal proteins in vitro. Abstract no. 866, 36th Interscience Conference on Antimicrobial Agents and Chemotherapy, New Orleans

167. Krijgsveld J, Zaat SA, Meeldijk J, van Veelen PA, Fang G, Poolman B, Brandt E, Ehlert JE, Kuijpers AJ, Engbers GH, Feijen J, Dankert J (2000) Thrombocidins, microbicidal proteins from human blood platelets, are C-terminal deletion products of CXC chemokines. J Biol Chem 275:20374-20381

168. Yeaman MR, Yount NY, Edwards JE Jr., Brass EP (2006) Multifunctional context-activated protides and methods of use. US patent number 7,067,621

169. Sieprawska-Lupa M, Mydel P, Krawczyk K, Wojcik K, Puklo M, Lupa B, Suder P, Silberring J, Reed M, Pohl J, Shafer W, McAleese F, Foster T, Travis J, Potempa J (2004) Degradation 
of human antimicrobial peptide LL-37 by Staphylococcus aureus-derived proteinases. Antimicrob Agents Chemother 48:4673-4679

170. Yount NY, Kupferwasser D, Spisni A, Waring AJ, Sharma S, Zachary Z, Ramjan H, Yeaman MR (2009) Selective reciprocity in antimicrobial activity versus cytotoxicity of hBD-2 and crotamine. Proc Natl Acad Sci USA (in press)

171. Schaffner A, King CC, Schaer D, Guiney DG (2004) Induction and antimicrobial activity of platelet basic protein derivatives in human monocytes. J Leukoc Biol 76:1010-1018

172. Zaiou M, Nizet V, Gallo RL (2003) Antimicrobial and protease inhibitory functions of the human cathelicidin (hCAP18/LL-37) prosequence. J Invest Dermatol 120:810-816

173. Trier D, Gank K, Kupferwasser D, Yount N, Bayer AS, Kupferwasser L, French WJ, Michelson A, Yeaman MR (2008) Platelet anti-staphylococcal responses occur through $\mathrm{P}_{2} \mathrm{X}_{1}$ and $\mathrm{P}_{2} \mathrm{Y}_{12}$ receptor-induced amplification and kinocidin release. Infect Immun 76:5706-5713

174. Sharma A, Novak EK, Sojar HT, Swank RT, Kuramitsu HK, Genco RJ (2000) Porphyromonas gingivalis platelet aggregation activity: outer membrane vesicles are potent activators of murine platelets. Oral Microbiol Immunol 15:393-396

175. Yeaman MR, Yount NY (2003) Mechanisms of antimicrobial peptide action and resistance. Pharm Rev 55:27-55

176. Mercier RC, Rybak MJ, Bayer AS, Yeaman MR (2000) Influence of platelets and platelet microbicidal protein susceptibility on the fate of Staphylococcus aureus in an in vitro model of infective endocarditis. Infect Immun 68:4699-4705

177. Mercier RC, Dietz RM, Mazzola JL, Bayer AS, Yeaman MR (2004) Beneficial influence of platelets on antibiotic efficacy in an in vitro model of Staphylococcus aureus endocarditis. Antimicrob Agents Chemother 48:2551-2557

178. Yeaman MR, Sullam PM, Dazin PF, Bayer AS (1994) Platelet microbicidal protein alone and in combination with antibiotics reduces Staphylococcus aureus adherence to platelets in vitro. Infect Immun 62:3416-3423

179. Yeaman MR, Sullam PM, Dazin PF, Ghannoum MA, Edwards JE Jr, Bayer AS (1994) Fluconazole and platelet microbicidal protein inhibit Candida adherence to platelets in vitro. Antimicrob Agents Chemother 38:1460-1465

180. Filler SG, Joshi M, Phan QT, Diamond RD, Edwards JE Jr, Yeaman MR (1999) Platelets protect vascular endothelial cells from injury due to Candida albicans. Abstract 2163, 39th ICAAC Meeting. American Society for Microbiology, San Francisco

181. Yeaman MR, Bayer AS (2000) Staphylococcus aureus, platelets, and the heart. Current Infect Dis Rep 2:281-298

182. Lorenz R, Brauer M (1988) Platelet factor-4 (PF4) in septicaemia. Infection 16:273-276
183. Mezzano S, Burgos ME, Ardiles L, Olavarria F, Concha M, Caorsi I, Aranda E, Mezzano D (1992) Glomerular localization of platelet factor 4 in streptococcal nephritis. Nephron 61:58-63

184. Wilson M, Blum R, Dandona P, Mousa S (2001) Effects in humans of intravenously administered endotoxin on soluble celladhesion molecule and inflammatory markers: a model of human diseases. Clin Exp Pharmacol Physiol 28:376-380

185. Sullam PM, Frank U, Yeaman MR, Tauber MG, Bayer AS, Chambers HF (1993) Effect of thrombocytopenia on the early course of streptococcal endocarditis. J Infect Dis 168:910-914

186. Dankert J, Krijgsveld J, van der Werff J, Joldersma W, Zaat SA (2001) Platelet microbicidal activity is an important defense factor against viridans streptococcal endocarditis. J Infect Dis 184:597-605

187. Viscoli C, Bruzzi P, Castagnola E, Boni L, Calandra T, Gaya H, Meuneir F, Feld R, Zinner S, Klastersky J et al (1994) Factors associated with bacteraemia in febrile, granulocytopenic patients. The International Antimicrobial Therapy Cooperative Group (IATCG) of the European Organization for Research and Treatment of Cancer (EORTC). Eur J Cancer 30:430-437

188. Feldman C, Kallenbach JM, Levy H, Thorburn JR, Hurwitz MD, Koornhof HJ (1991) Comparision of bacteraemic communityacquired lobar pneumonia due to Streptococcus pneumoniae and Klebsiella pneumoniae in an intensive care unit. Respiration 58:265-270

189. Chang FY, Singh N, Gayowski T, Wagener MM, Mietzner SM, Stout JE, Marino IR (2000) Thrombocytopenia in liver transplant recipients: predictors, impact on fungal infections, and role of endogenous thrombopoietin. Transplantation 69:70-75

190. Smith-Erichsen N (1985) Serial determinations of platelets, leukocytes, and coagulation parameters in surgical septicemia. Scand J Clin Lab Invest 178:7-14

191. Santolaya ME, Alvarez AM, Aviles CL, Becker A, Cofre J, Enriquez N, O'Ryan M, Paya E, Salgado C, Silva P, Tordecilla J, Varas M, Villarroel M, Viviani T, Zubieta M (2002) Prospective evaluation of a model of prediction of invasive bacterial infection risk among children with cancer, fever, and neutropenia. Clin Infect Dis 35:678-683

192. Yoshida T, Tsushima K, Tsuchiya A, Nishikawa N, Shirahata K, Kaneko K, Ito K, Kawakami H, Nakagawa S, Suzuki T, Kubo K, Ikeda S (2005) Risk factors for hospital-acquired bacteremia. Intern Med 44:1157-1162

193. Mavrommatis AC, Theodoridis T, Orfanidou A, Roussos C, Christopoulou-Kokkinou V, Zakynthinos S (2000) Coagulation system and platelets are fully activated in uncomplicated sepsis. Crit Care Med 28:451-457

194. Sun H, Wang X, Degen JL, Ginsburg D (2009) Reduced thrombin generation increases host susceptibility to group A streptococcal infection. Blood 113:1358-1364 